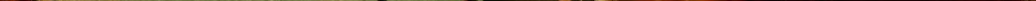




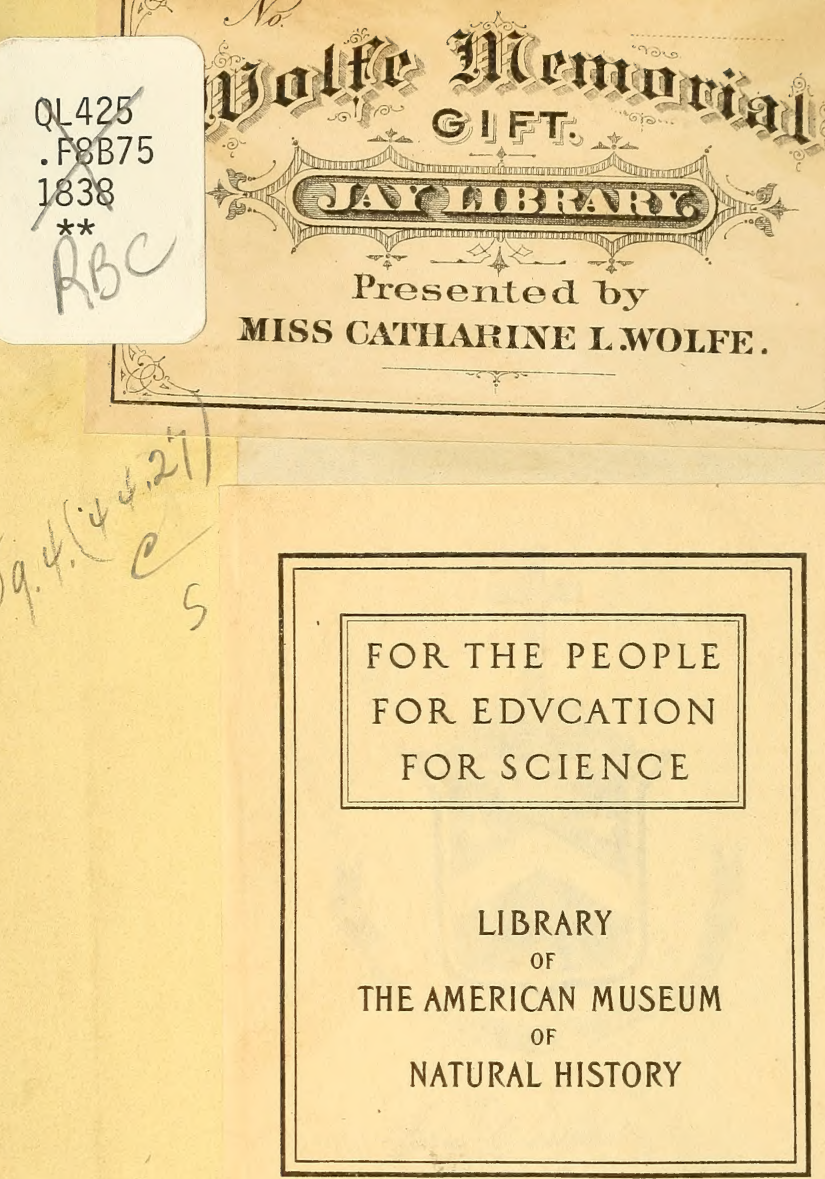




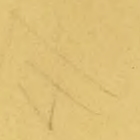

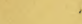









\title{
CATALOGUE
}

\section{DES MOLLUSQUES}

\author{
OBSERVÉS L L'ÉTAT VIVANT
}

DANS LE DEPARTEMENT DU PAS - DE - CALAIS.

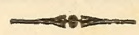




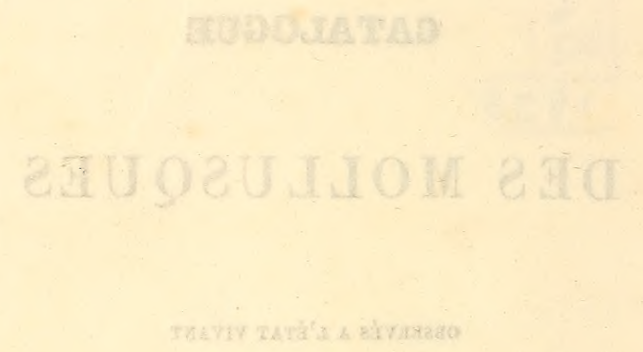

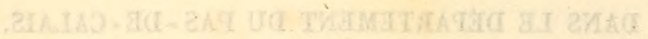




\section{CATALOGUE}

DES

\section{MOLLUSQUES}

Terrestres et Fiuviatiles

OBSERVÉS JUSQU'A CE JOUR A L'ÉTAT VIVANT .

DANS LE DĹPARTEMENT DU PAS-DE-CAMAN,

\section{PAR \\ M. BOUCHARD-CHANTEREAUX,}

Membre de plusieurs Sociétés savantes.

(Présenté à la Sociélé d'Agricullure, Sciences et Arts de Boulogne-sur-

mer, le 2 Septembre 1836.)

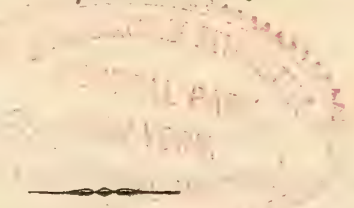

MOIIDGXE:

Imprimerie de Le Roy-Mabille, Grande Rue. 1838. 
$=$

Hin in wh

1

11

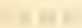

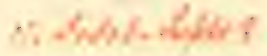

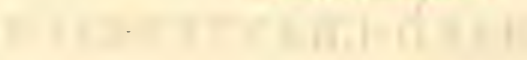




\section{CATALOGUE}

\section{DES MOLLUSQUES}

TERRESTRES ET FLUVIATILES

Observés jusqu'à ce jour à l'état vivant

DANS LE DÉPARTEMENT DU PAS-DE-CALAIS.

G ÉNÉ RALITÉS.

C'est des fréquentes comparaisons auxquelles on soumet un sujet que jaillit la clarté nécessaire pour le bien voir.

Les Limaces, comme chacun sait, sont des animaux semi-nocturnes qui ne sortent ordinairement de leur retraite, le plus souvent établie dans un lieu environné de substances propres à leur nourriture, que lorsque le soleil est sur son déclin, ou que ses rayons sont interceptés par un temps nuageux ou pluvieux; on les voit alors ramper aux environs de leur demeure, de laquelle ils ne s'éloignent que rarement, et où ils retournent aussitôt que. les rayons solaires commencent ì les incommoder. 
Les habitudes des autres Limacinés ne diffèrent de celles des Limaces, qu'en ce qu'ils n'ont point, comme la plupart de celles-ci, de demeures habituelles, et que, pour s'abriter des chaleurs diurnes, ils se cachent sous les corps qui les environnent, ou ferment leur coquille au moyen d'un épiphragme vitreux qui les fixe en même temps aux tiges des plantes herbacées sur lesquelles ils vivent. Tous ont le corps couvert de rugosités plus ou moins prononcées, et séparées par des petits sillons proportionnés à celles-ci, qui servent à répandre, sur toute la surface du corps, l'humeur visqueuse produite par les pores de la peau, qui la lubrifie, et sert à la reptation de ces Mollusques, qui ne peuvent avancer qu'en expulsant une partie de cette humeur dont ils laissent sur le sol, après leur passage, une couche d'autant plus épaisse que le plan sur lequel ils rampent est humide, sec ou absorbant. Une trop grande transsudation de ce Mucus les affaiblit considérablement; mais ils n'ont recours à ce moyen, le seul qui soit en leur pouvoir pour se défendre, que lorsqu'ils courent quelque danger, soit attaqués par d'autres animaux qui en font leur nourriture, soit lorsqu'ils sont surpris par les rayons trop brûlants du soleil, ou encore lorsqu'ils se sont aventurés sur un sol trop absorbant. Dans les deux premiers cas, l'animal transsude de toutes les parties de sa peau, un Mucus qui devient, au fur et à mesure que celui-ci s'épuise, de plus en plus épais et opaque, et qui à sa mort forme une couche qui a quelquefois plus d'une ligne d'épaisseur recouvrant toute sa surface. Dans le dernier de ces cas, l'individu rampe tant qu'il peut produire le Mucus nécessaire à cet acte; mais comme le plan sur lequel il se trouve, en $a b$ sorbant plus vîte l'humidité de cette matière, en nécessite une plus grande quantité que celle qu'il peut secréter, il 
fait des efforts superflus, sa peau se dessèche ; il perd ses forces et meurt. C'est ainsi qu'on en trouve souvent de desséchés sur les murs plâtrés et badigeonés des habitations champêtres.

Les jardiniers, dont ces Mollusques causent souvent le désespoir en détruisant dans une seule nuit leurs plus chères espérances, leur font une guerre continuelle: quelques-uns d'entre eux ayant remarqué que leur reptation nécessite un sol résistant, couvrent, vers le soir, d'une couche de paille très-finement hachée, les plantes déjà endommagées, et les environs des retraites de ces mollusques que l'on reconnaît aux traces laissées à leur passage, par le mucus qui, en se détachant, devient friable et brillant. Celte paille hachée, en s'attachant à leur plan locomoteur, les empêche de ramper, les chatouille, et provoque chez eux une plus grande transsudation de Mucus, dont ils ne peuvent se débarrasser, ce qui les en empêtre davantage; en sorte que si le jardinier ne les trouve pas morts à son arrivée le matin, il peut au moins les achever facilement.

A l'époque du Rut, et surtout pendant leur accouplement, les Limacinés transsudent encore beaucoup plus de Mucus que d'ordinaire; aussi lorsque cet acte est terminé, paraissent-ils très-affaiblis, et pour récupérer les pertes qu'ils viennent de faire, dévorent-ils avec avidité la première nourriture qu'ils rencontrent.

Outre leMucus ordinaire que transsude la peau de ces mollusques, les $\boldsymbol{A}$ rions en produisent un autre par le $\boldsymbol{S} i$ nus aveugle de l'extrémité postérieure de leur corps; celui-ci est constamment très-épais, et jouit d'une toute auire propriété que celui expulsé par la peau. A l'époque du rut il est aussi plus abondant qu'à toute autre époque; il forme au-dessus du sinus un globule qui, chez les grosses espèces de cegenre, atteint quelquefois dix millimètres de 
diamètre. Lorsque deux individus se rencontrent, l'un d'eux se dirigeant aussitôt vers l'extrémité postérieure de l'autre, qui continue à ramper, lui pose, en l'atteignant, sa tête sur la queue, et tout en suivant la même direction mange très-lentement le Mucus que celle ci produit, jusqu'à ce que le premier, se retournant (ce qui demande ordinairement environ deux heures), vienne caresser le côté droit de la tête du second; alors ce dernier, abandonnant le Sinus, lui rend les mêmes caresses; ils continuent ainsià se caresser mutuellement la bouche et l'orifice des organes de la génération pendant environ trente à quarante minutes; alors cet orifice se dilatant, laisse voir le tubercule commun de ces organes; un rapprochement plus intime a lieu, et l'accouplement s'opère.

Chez les Limaces, les préludes de l'accouplement se bornent à des caresses que se font mutuellement avec la bouche deux individus qui se rencontrent, et qui sont disposés à cet acte. Ils tournent d'abord au tour l'un de l'autre en se caressant les diverses parties du corps; puis, resserrant le cercle qu'ils forment, ils se caressent principalement la tête et l'orifice ou les environs de l'orifice des organes de la génération; pendant ces diverses caresses, qui ne durent quelquefois qu'un quart d'heure, leur organe excitateur est toujours développé, et ce n'est que lorsque la base de ces organes se trouve en contact, que les autres organes se développent et s'entrelacent; mais cela a lieu avec une rapidité telle, qu'il est impossible d'en saisir le mécanisme.

Je fus un jour témoin d'un mouvement de colère très . prononcé chez une Limace agreste, qui avait des dispositions à s'accoupler, et qui, en rencontrant une autre qui n'en avait pas, lui fit, pendant à peu près une demiheure, les caresses qui précèdent ordinairement cet acte. 
sans que celle-ci les lui rendit : fatiguée sans doule de la carcsser inutilement, elle fit un mouvement de tête trèsprévipité, et la mordit au mufle, puis s'éloigna d'elle.

J'ai observé, depuis une dixaine d'années, plus de deux cents accouplements dans les diverses espèces d'Hélices de notre pays, et je ne les ai jamais vu se lancer le dard vénérien; je l'ai cependant trouvé quelquefois, soit entré plus ou moins profondément dans l'un des côtés du pied de nos Helix aspersa, nemoralis et hortensis, soit seulement collé au moyen d'une humeur visqueuse, hyaline et incolore qui l'entourait. Loin de penser que ces animaux en produisent un nouveau à chaque accouplement, comme le disent quelques auteurs, je crois que ce dard n'existe que chez les individus qui effectuent l'accouplement pour la première fois, et qu'il est chez eux un signe de virginité, ou enfin que cet organe est destiné à quelque autre usage. J'ai vu renouveler plusieurs fois cet acte par des Hélices que je conservais chez moi et que j'observais avec la plus grande attention, mais je n'ai jamais pu apercevoir ce dard, quoique je misse tous mes soins à observer ces Hélices chaque fois même où elles procédaient aux préludes de leur accouplement.

Désirant vivement, enfin, m'assurer de ce fail, je me procurai des Hélices au moment de leur hibernation, étant persuadé qu'ainsi j'observerais leur premier accouplement de l'année. Au printemps suivant, en effet, j'observai de nouveau plusieurs fois cet acte et ses préludes, et ne vis pas l'ombre de dard vénérien; donc, le plus ordinairement, l'accouplement a lieu sans qu'il figure dans ses préludes, qui, du reste, sont à peu près les mêmes que ceux des Limaces, et dont ils ne diffèrent qu'en ce que les Hélices, comme la plupart des autres Limacinés qui les suivent, arrivées en face l'une de l'autre, relèvent en- 
viron la moitié de leur plan locomoteur, et, les appliquant l'un contre l'autre, se mordent pendant environ un quart d'heure mutuellement la tête; à chaque morsure, l'individu qui la reçoit rentre ses tentacules, et les développe quelques secondes après : quand la morsure est par trop forte, ils se séparent quelques instants, se recherchent et reprennent leur première position. Enfin pendant ce temps, les organes de la génération se sont développés, les deux individus se séparent, et, rapprochant chacun leur côté droit, effectuent l'accouplement. La réunion des organes nécessaires à cet acte n'a pas lieu de la mêmc manière chez tous les Limacinés, et la forme de ces organes varie dans plusieurs genres. Les Limaces possèdent un organe que l'on ne retrouve plus dans les autres genres qui les suivent; c'est l'organe excitateur dont je veux parler, que quelques auteurs ont improprement nommé verge, puisqu'il ne participe pas à la copulation, et ne sert, comme son nom l'indique, qu'à provoquer cet acte. Il est pyriforme, strié longitudinalement, et varie de cou. leur, même chez les individus appartenant à la même espèce; il est tantôt blanc, gris ou brun clair : il est fendu longitudinalement à la partie inférieure de sa jonction avec le corps, pour donner passage aux organes des deux sexes. Lorsque les deux individus ont assez approché leur côté droit l'un de l'autre, ils relèvent chacun cet organe do manière à ce que leur base, qui alors est passablement gonflée, se touche, se lancent et entrelacent en un clind'œil leurs organes génitaux qui forment une masse arrondie d'un blanc bleuâtre, qui seule sépare les deux individus sur le côté desquels on voit encore la pointe de l'organe excitateur, placée verticalement, et sur laquelle on dislingue un trémoussement précipité. Leur manteau, très-contracté en arrière, laisse voir au travers de la peau du cou un mouvement ondulatoire; ils paraissent souffrir; 
leurs tentacules sont rétractés; ils allongent la têle et ouvrent la bouche comme s'ils voulaient mordre, retirent leur tête sous le manteau, l'allongent de nouveau, el re commencent ainsi pendant environ une demi-heure, puis paraissant affaissés; ils retirent définitivement leur tête sous le manteau, jusqu'à ce que cet acte soit terminé. Alors les deux individus se séparent, et ne font rentrer que très-lentement le tubercule, encore gonflé, qui sert de base aux organes des deux sexes, et sur lequel on voit l'orifice de chacun placé verticalement; celui de la verge au-dessus de celui de l'oviducte; souvent chaque animal lèche ce tubercule jusqu'à ce qu'il soit entièrement rentré. Les mêmes organes m'ont paru plus simple chez les Hélices; d'abord, comme je l'aî dit plus haut, privés d'organe excitateur, eux-mêmes en font les fonctions, étant développés pendant les préludes de l'accouplement, et beaucoup plus gonflés alors, que durant cet acte, qui fait aussi disparaître complètement le tubercule commun. Ce tubercule en porte un autre un peu plus petit à sa partie antérieure, au centre duquel est l'ouverture de l'oviducte; et à sa partie postérieure, lout à côté du précédent, un autre tubercule trois fois plus petit que lui, qui sert de base à la verge, et dans lequel elle se rétracte; celle-ci est tout-à-fait cylindrique chez certaines espèces, et chez d'autres, porte à son extrémité un renflement plus ou moins plissé, en forme de fer de lance ou de harpon; l'accouplement de ces derniers dure bexucoug plus long. temps que celui des autres. Enfin quand deux individus sont disposés à effectuer cet acte, ils n'ont qu'à introduire mutuellement leur verge dans l'oviducte, et ne se lancent point cet appareil comme le font les Limaces.

Les Ambrottes offrent une différence dans la position de ces organes, qui, du reste, sont semblables à ceux des 
Hélices: c'est que la verge, aussi renflée à son extrémité, est située au-dessous de l'ouverture de l'oviducle; ce qui force, lors de l'accouplement, l'un des deux individus à décrire une demi-révolution. Pendant la copulation, le cœur de ces Mollusques donnait 50 à 60 pulsations à la misute.

Plusieurs accouplements ont toujours lieu avant la ponte chez les mêmes individus, et c'est à peu près douze ou quinze jours après le premier qu'elle s'effectue; alors, le plus ordinairement, les Limacinés choisissent les lieux couverls et humides, et y creusent des trous en terre; ces trous sont toujours d'une profondeur proportionnée à la longueur de la partie antérieure du corps de l'animal, si celui-ci est une Hélice, sa coquille reste le plus souvent à la surface du sol; les Arions et les Limaces pénè. trent entiěrement dans ceux qu'ils creusent; et les petites espèces de Bulimes, de Clausilies et de Maillots y font entrer les deux tiers antérieurs de leur coquille, puis creusent une petite galerie latérale, arrondie et proportionnée à la masse d'œufs qu'elle doit contenir, mais qui ne la remplit jamais. Pendant toute la durée de la ponte, l'animal ne bouge pas; les Arions et les Limaces ont le corps complètement ramassé; leur manteau est contracté et reliré en arrière comme pendant l'accouplement, et leurs tentacules sont tout-à-fait rétractés. Les $H$ élices et autres Limacinés ont aussi leurs tentacules rétractés, mais la partie antérieure de leur corps est considérablement allongée. L'œuf paraissant à l'orifice des organes génitaux met une à trois minutes à en sortir, et l'intervalle entre l'expulsion de chaque œuf est de quatre à quinze minuŁes, et quelquefois plus, dans les petites espèces. La ponte une fois terminée, l'animal se retire, et remplit de terre le trou qu'occupait son corps, puis l'abandonne pour ne 
plus y revenir; il paraît épuisé, sa peau est aride, et ce qui est surtout remarquable chez les Limaces, c'est que leur corps est diminué de plus de la moitié. La durée de la ponte, qui a quelquefois lieu à deux ou trois reprises, varie de vingt à quarante heures, et son produit varie aussi suivant les espèces, comme on le verra dans ce ca talogue, mais n'est jamais moindre de dix à quinze œufs, comme dans les Clausilies et les Maillots, et ne dépasse guère cent à cent dix, comme dans l'Arion des Charlatans et l'Helix aspersa. Il offre cependant une exception en faveur de la Limace agreste, qui multiplie considéra. blement, et dont la ponte s'élève quelquefois à près de deux cents œufs déposés en six ou huit reprises, à des intervalles de trois semaines à un mois, mais $\grave{x}$ chacune desquelles un nouvel accouplement au moins est nécessaire; en sorte que sa ponte se continue pendant toute la belle saison, tandis que les autres Limacinés, dans le même temps, ne font qu'une seule ponte qui, comme je l'ai déjà dit, a quelquefois lieu en deux ou trois reprises, qui ne demandent pas plus de trois ou quatre jours, sans accouplement nouveau, et dont la première contient toujours au moins les six-huitièmes de la totalité des œufs composant leur ponte. Tous les individus appartenant à une même espèce, n'ayant pas la même taille, et tous multipliant avant d'avoir atteint leur dernier degré d'accroissement, leurs œufs se ressentent de cette différence, et sont proportionnés à leur taille; mais ceux pondus par un individu ne diffèrent pas sensiblement entre eux. Il n'en est pas de même quand l'on compare ceux de certaines espèces entre elles: sourent on remarque une disproportion très-prononcée entre les animaux et leurs œufs; ainsi ceux de l'Hélix Carthusiana n'ont qu'un millimètre et demi de diamètre, tandis que ceux de l'Hé- 
lix hortensis, qu'elle égale en grosseur, en ont cnviron trois, et que cenx de l'II élix carthusianelln, moitié plus pelite que ces deux espèces, ont un diamètre d'un millimètre un quart. Cette disproportion est encore bien plus sensible quand l'on compare ensuite les animaux des espèces citées avec ceux des Clausilia bidens, rugosa et pupa fragilis, qui sont au moins vingt fois plus petits, et dont les œufs sont à-peu-près aussi gros. Tous ces œufs conservent jusquà lcur éclosion la forme et la grosseur qu'ils ont au sorlir de l'oviducte; mais il est impossible qu'ils aient celte grosseur dans l'intérieur du corps de ceux qui les produisent, puisque, la ponte terminée, la masse qu'ils forment est souvent plus grosse que l'individu qui l'a pondu; il faut nécessairement que ces œufs alteignent ce volume dans le trajet qu'ils fout de l'ovaire à leur sortie, grossissement très-rapide, sans donte, puisque l'intervalle le plus long que j'aie observé entre la ponte de chaque œuf est de douze à quinze minutes.

Les œufs des Limaces, ordinairement ovales, rarement globuleux, sont ou réunis en chapelets par un prolonge. ment de leur enveloppe externe, ou isolés, mais toujours transparents : ceux des Arions sont toujours ovales, isolés et opaques; enfin ceux des autres Iimacinés, aussi toujours isolés, sont ovales ou arrondis el plus ou moins opaques. J'ai remarqué chez ces derniers que l'enveloppe externe de leurs œufs est d'autant plus calcsire ou crélacée, que la coquille de l'individu qui les a pondus est épaisse ou solide; ainsi, les coquilles des Hélix Pomatia, Aspersa et Nemoralis, étant de nos localités, les espèces les plus épaisses, l'enveloppe externe de leurs œufs est aussi bien plus calcaire que celle de ceux des Hélix. Carthusiana et Revelata, dont les coquilles sont fort minces, et les enveloppes externes de leurs œuls, entièrement mucoso-cornées et translucides. 
Ces œufs, comme ceux des oiseaux, sont composés des parties suivantes : d'une coque ou enveloppe exlérieure, calcaire ou crétacée ct opaque, ou mucoso-cornée plus ou moins transparente : de la membrane de la coque trèsmince, et tout-à -fait hyaline; d'un albumen très-limpide; d'un vitellus et d'une cicatricule grisâtre et arrondie, que l'on n'aperçoit qu'avec le secours d'une bonne loupe. Le jaune ou vitellus, ayant une apparence albumineuse, se distingue difficilement de l'albumen proprement dit, étant transparent comme lui, et seulement un peu plus épais; niais aussitôt que l'on plonge un de ces oufs dans l'alcool, il devient très-visible, étant alors entièrement opaque, tandis que l'albumen conserve sa transparence.

Bien que ces Mollusques recherchent ordinairement les. lieux humides pour y déposer leurs oufs, ceux-ci peuvent supporter les sécheresses les plus prolongées, sans qu'elles nuisent'en aucune manière à leur vitalité, qu'ils conservent, quoique enlièrement desséchés, très - long-temps; elles ne retardent que leur éclosion. J'ai conservé pendant plusieurs années des œufs de la plupart des $L i$ macinés de notre pays; ils étaient tellement desséchés que leur forme globuleuse ou ovoïde, entièrement disparue, élait réduite à une simple peau friable entre les doigts; une heure d'humidité leur suffisait cependant pour qu'ils reprissent leur forme et leur élasticité primitive; et si, par une nouvelle dessiccation, je n'arrêtais pas le développement de l'embryon, l'époque arrivée ils éclosaient comme ceux sur lesquels je n'avais point fait de semblable expérience.

Les variations atmosphériques influent considérablement sur le temps à parcourir entre la ponte de ces oufs et leur éclosion; en sorte que des œufs pondus dans les mois de Mai ou Juin écloront du quinze au vingtième jour 
de leur ponte; tandis que d'autres, pondus par un individu de la même espèce, en Octobre ou en Novembre, mettront deux ou tiois fois autant de temps à subir la même opération. Il en est de même pour la croissance des jeunes individus qui, nés dans la saison des chaleurs, croîtront bien plus rapidement que ceux nés en Décembre ou Janvier, qui ordinairement restent stationnaires pendant deux ou trois mois, étant engourdis en terre, où ils passent tout l'hiver. Les pelits, au sortir de l'ceuf, ont déjà toutes les formes qu'ils doivent conserver, et si leur mère est recouverte d'une coquille, celte pièce existe aussi, mais n'a pas alors la forme turbinée; si elle appartient à cette famille, elle est discoïde et ne recouvre pas encore entièrement l'animal; sa tête et une partie du cou restent encore à couvrir; ce n'est qu'environ vingt-quatre heures après son éclosion', que le petit animal passe ordinaire. ment en repos, que les bords du manteau, dépassant la coquille, forment, par leur transsudation, la partie nécessaire pour l'abriter entièrement. Cette petite coquille qui n'avait, au sortir de l'œuf, qu'environ un tour de spire, en a alors un et quart à un et demi; elle est toujours, n'imporle la couleur de l'espèce à laquelle elle appartient, plus ou moins cornée et transparente; et l'orsqu'elle provient d'espèce hispide, elle est déjà couverte d'un grand nombre de petits poils raides et roux, et d'autant plus forls qu'ils approchent de son péristome. Leur croissance ensuite dépend beaucoup du plus ou moins d'abondance de nourriture qu'ils ont à leur disposition; ils atteignent cependant leur dernier degré d'accroissement vers la fin de leur première année, ou dans le premier mois de la seconde, mais tous se reproduisent avant d'avoir atteint ce terme.

Les Trachélipodes aquatiques suintent aussi par les 
pores de leur peau une humeur visqueuse qui (I), à la vérité, est beauccup moins épaisse et abondante que chez les Limacinés, n'ayant point à craindre comme eux l'influence des agents extérieurs, mais qui est indispensable à leur reptation, et surtout à celle que certains d'entre eux exécutent à la surface de l'eau, le corps renversé; ces derniers, c'est-à dire les Limnées, Planorbes et Physes jouissent aussi d'un autre mode de locomotion qui leur est propre; ils peuvent, à leur volonté, s'élever ou descendre au milieu de l'élément oủ ils vivent au moyen de l'air contenu dans leur cavité respiratrice, qu'ils dilatent, compriment ou rejeltent, suivant l'un de ces modes qu'ils veulent employer. Lorsqu'ils descendent avec rapidité, on voit très-distinctement les bulles d'air s'échap. per de cette cavité. L'organisation de ces Mollusques est dejà trop connue pour que je m'en occupe ici; je répare rai seulement deux erreurs commises par Trevirranus. Cet estimable savant dit $1^{\circ}$ que la verge du Planorbe corné est imperforée, et présente simplement une gouttière qui communique à la base du Pénis avec le déférant. J'ai plusieurs fois observé l'accouplement des Planorbes, et j'ai remarqué que, pendant cet acte, les Planorbes corné et marginé ( espèces les plus fortes de nos localités), avaient leur verge tellement gonflée, qu'elle était entièrement transparente; je vis alors très-distinctement leur canal éjaculateur, dans lequel passait, à sept ou

(1) Je ne puis résister au désir de témoigner de noureau ici loute mon admiration pour la précieuse découverte de M. Charles Des Moulins, de Bordeaux, qui m'a permis d'avoir constamment chez moi depuis six ans presque toutes les espèces de Mollusques fluviatiles de notre pays; et sans laquelle la plupart des faits relatés dans ce catalogue me seraient encore inconnus, ne pensant pas qu'il soit possible de les observer dans les lieux où vivent ordinairement ces animaux. 
huit reprises, le liquide fécondateur blanc et opaque lancé comme une petite fusée; chaque fois le tentacule gauche seulement se contractait et se développait aussitôt ; $2^{\circ}$ que la verge de la Paludine vivipare a sa sortie à la base du tentacule droit. Les autres espèces de ce genre ont bien la sortie de leur verge à la base du tentacule droit; mais je me suis assuré, en séparant plus de vingt individus accouplés, que celle de la paludine vivipare sortait par l'extrémité de ce tentacule, et non par sa base, qui est constamment visible pendant cet acte. Celte verge est blanche, grèle, un peu comprimée, et terminée en pointe mousse; elle est aussi longue que ce tentacule dans lequel, cet acte terminé, elle se retire lentement.

Pendant la saison des chaleurs, ces mollusques se recherchent pour s'accoupler; mais cet acte, chez eux, ne nécessite point de préludes : le mâle, ou celui destiné à en faire les fonctions, rampe sur la coquille d'un autre individu de son espèce, et, parvenu sur le bord du côté où sont situés les organes de la génération, il introduit sa verge dans l'oviducle. Pendant l'accouplement, qui dure ordinairement deux ou trois heures, leur cœur donne quarante-cinq à cinquante pulsations à la minute : les individus faisant les fonctions de femelle paraissent beaucoup plus souffrir que les autres; ils ont les tentacules tombant négligemment sur leur mufle, ils se frottent la tête sur les corps environnants, et rentrent de temps en temps et trèsbrusquement la tête dans leur coquille. Plusieurs accouplements leur sont aussi nécessaires avant la ponte, et celle ci ne commence que six à huit jours après le pre. mier: elle a lieu soit en une seule fois, soit en six ou huit reprises, et à des intervalles d'au moins vingt-quatre heures, sans que l'animal ail besoin d'être de nouveau fécondé. 
Les Limnéens, auxquels je joins les Ancyles dont les animaux ont les principaux caractères, pondent tous des wufs globuleux ou ovoïdes et hyalins, de grosseur pro. portionnée aux animaux dont ils proviennent, et dissémi . nés dans une matière gélatineuse transparente, incolore ou légèrement ambrée, de formes diverses, et enveloppée d'une membrane lisse ou striée. Les œufs des Ancyles et des Planorbes sont contenus, en très-petit nombre, dans des petites capsules orbiculaires mucoso-cornées, jaunâtres et striées, fixées sur les pierres ou sur les tiges des moyennes plantes aquatiques; ceux des Physcs et des Limnées, le plus sourent très-nombreux, sont réunis dans des masses plus ou moins cylindriques ou arrondies de diverses grosseurs, de matière gélalineuse transparente, et enveloppée d'une membrane lisse et incolore, couverte d'une couche de Mucus qui les fixe aux corps sous-marins. Le développement de l'embryon de ces œuf́s a lieu plus rapidement, et est aussi plus régulier que celui de l'embryon des œufs des Limacinés; la cause, sans doute, est le peu d'influence qu'ont, à celte époque, sur le milieu où ils sont déposés, les variations atmosphériques. Pendant les sept à huit premiers jours, l'embryon, qui a une forme arrondie, augmente sensiblement de volume; il se contracte, se dilate et éproure des mouvements rotaloires; on voit sur l'un des points de sa circonférence une petite galette, c'eux liers moins forte que lui, composée de très-petites globulss succinés el toutà-fait hyalins; le dixième jour, des mourements de translation ont remplacé ceux de rutation; on distingue les diverses parties qui doivent composer le jeune animal, et qui se perfectionnent de jour en jour jusqu'à son éclosion, qui arrive le quinzième ou seizième jour; deux jours avant celte éclosion son cœur donne $z^{5}$ à 80 
pulsations à la minute. Le jeune individu rampe, aussitôt sa sortie de l'œuf, sur les corps qui l'environnent; il a aussi toutes les formes de son espèce; mais si son développement embryonaire est plus rapide que celui des $L i$ macinés, le nouveau qui lui reste à effectuer est bien pl'ss lent, puisqu'il n'atteint son dernier degré d'accroissement que vers la fin de sa seconde année. 


\section{CATALOGUE}

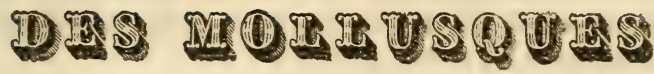

TERRESTRES ET FLUVIATILES

Observés à l'état vivant

DANS LE DÉPARTEMENT DU PAS-DE-CALAIS.

\section{ORDRE $1^{\mathrm{ex}}$.}

\section{GASTÉROPODES. Guvier.}

Genre Arion. Arion de Férussac.

N. 1. Arion des Charlatans. Arion Empiricorum.

Fèrussac, histoire naturelle, générale et particulière des Mollusques terrestres et fluviatiles, page 60 , planche 1 à 3 .

Supplément, p. 96. z, $\mathrm{n}^{6} 1$.

Tableaux systématıques des animaux Mollusques, p. 17, n. 1.

Draparnaud, histoire naturelle des Mollusques terrestres et fluviatiles de la France, p. 122, n. 2, 3, pl. 9, f. 3-6.

Lamarck, animaux sans vertèbres, t. 6, 2me partie, p. 49, n• 1 .

Blainville, Dictionnaire des Sciences naturelles, t. 26, p. 426.

Brard, Histoire des Coquilles des environs de Paris, p. 123.

Charlcs dos Moulins, Catalogue des Mollusques du départ. de la

Gironde, bulletin de la société Linéenne de Bordeaux, t. 2 p. $44, \mathrm{n} \cdot 1$.

Grateloup, Tableau méthodique des Mollusques terrestres et fluviatiles de l'arrondiss. de Dax, Bull. soc. Linn. Bordeaux, t. 3, p. 53 et $55, \mathbf{n} \cdot \mathbf{1}$ et $\mathbf{3}$.

Collard des Cherres, Catalogue des Testacés terrestres et fluviatiles des environs de Brest et de Quimper, Bull. soc. Linn. Bordeaus t. 4, p. $94, \mathrm{n} \cdot 1$.

Kickz, Synopsis Molluscorum Brabantiæ, p. 1 à 3. 
Michaud, Complément de Draparnaud, p. 3, 4, n· 1-3.

Millet, Tableau méthodique des Mollusques terrestres et fluviatiles du départ. de Maine-et-Loire; Actes de la société Linéenne de Bordecux, t. 6, p. 115, n 1 .

Bouillet, Catalogue des Mollusques terrestres et fluviatiles de l'Auvergne: page 11 et $12, \mathrm{n} \cdot 1$ et 3 .

\section{VARIETES.}

1. Aterrimus totus vel brinneus Drap. Fer. pl. 2, f. 1.

2. Niger, Margine lutescente, aut coccineo, Drap.

3. Nigricans, margine lutescente aut coccineo, Drap. Fer. pl. 2, f. 2.

4. Obscure rufus, margine lutescente aut cocci neo Drap.

5. Tolus rufus, Fer, pl, 3, f. 2.

6. Totus ruber, Fer. pl. 1, f. 1, 2, 5.

7. Flavescens, Fer. pl. 1, f. 4.

8. Obscure fuscus, utrinque lutescente aut croceo, Fer. pl. 1, f. 6, 7.

9. Albus, margine flavo, Fer. pl. 2, f. 3.

10. Albus, margine et sincipite aurantio, Fer.

Habite tous les lieux humides, les prairies, les Jardins. Très-commun et varié dans sa coloration. La première variété habite nos falaises, où elle est seule et constamment noire; l'A. blanc de Muller n'est pour moi qu'une variété de celle-ci; car, quoique assez rare, je l'ai toujours trouvé avec l'A. empiricorum, dont il ne diffère que par la couleur. Quant aux variétés figurées dans Férussac, pl. $1^{\mathrm{re}}$, fig. $6,7,8$, ce sont de jeunes individus dont les premiers sont âgés à peu près de six mois, et le dernier de quatre mois. Ces Arions pondent de Juin à Octobre, et leurs œufs, au nombrede soixante-dix à cent, metlent vingt-six à quarante jours à éclore : ces œufs sont ovales, à enveloppe calcaire, de couleur blanc-bleuâtre ou blancjaunâtre, opaques; leur diamètre longitudinal est d'environ quatre millimètres, et le transversal de trois millimètres et demi. Les jeunes individus atteignent leur dernier degré d'accroissement vers la fin de leur première 
année; ils ont alors environ seize centimètres de lonģueur sur dix-huit millimètres de hauteur, et vingt-deux millimètres de largeur. (1)

N.2. Arton Jadne. Arion flavus.

Fèrussac, Hist. Moll., supp., p. 96, b, n· \%.

Tabl. syst., p. 24, n· 3.

Blainville, Dict. sc. nat., t. 26, p. 432.

\section{VARIETES.}

1. Flavus capite et tentaculis nigris. Fér.

2. Albidus, clypeo et corpore subtus sublutris, capite et tentaculis nigr1 cantibus. Fer.

3. Pallidus, Clypes flavo, dorso subcinerascente. Fer.

4. Griseus, capite et tentaculis nigris.

Description; dos jaune citron, plus ou moins foncé, quelquefois grisâtręe, couvert de rides anastomosantes, manteau court, arrondi à ses deux extrémités, finement granuleux; côté du corps plus clair que le reste; queue d'une belle couleur orange, chez les individus dont la couleur est jaune foncé, et jaune chez la seconde et troisième variété. Tête noirẫtre coupée au milieu par deux petits sillons longitudinaux qui s'étendent sur le cou; Tentacules noirs, courts et gros, les inférieurs un demimillimètre, les supérieurs deux millimètres. Ces tentacules sont si foncés, que l'on ne peut apercevoir les yeux qu’à la loupe. Orifice respiratoire fort petit, situé au tiers antérieur du côté droit du manteau. Pore muqueux, triangulaire, s'étendant en une petite rigole jusqu'à l'extrémité de la quẹue. Plan locomoteur divisé en trois bandes longitudinales, celle du centre (le pied) de couleur bleu

(1) Les dimensious sont toujours celles de l'individu rampant. 


\section{4}

ardoise; les deux autres jaunes, bordées d'une ligne orangée. Mucus abondant, très-śpais, de couleur jaune orangé.

Longueur, trente millimètres; largeur, trois millimètres; hauteur, dans sa partie la plus élevée, qui est l'endroit où est placé l'orifice de la cavité pulmonaire, trois millimètres.

Ce Mollusque mulliplie très-peu; il dépose ses œufs, au nombre de quaranteà cinquante, en cinq à six jours, dans les mois de Septembre à Décembre. Ces œufs sont ovales, jaunâtres et opaques; ils ont un millimètre et demi de long sur un millimètre un quart de large, et n'éclosent que vingt-cinq à quarante jours après leur ponte; les petits atteignent leur dernier degré d'accroissement vers la fin de leur première année. Cette espèce n'appartient point à la précédente, comme le dit M. de Blainville; elle habite les lieux humides et couverts de mousse de nos falaises.

- N. 3. Anton des Jandins, Arion hortensis.

Fèrussac, Hist. Moll. p. 65, n. 4, pl. 2, f. 4, 6 ct pl. 8 A, f. 2, 4. Supp.p. 96 a n. 5 .

Tableau syst. p. $1 S_{;} n \cdot 6$.

Blainville, Dict. sc. nat, f. 26, p. 429.

Bouillet, Loc. cit. p.13, n. 4.

Limax fasciatus Kickx, loc. cit. p. 4, n-3.

\section{VARIÉTÉS.}

1. Griseus unicolor, fasciis nigris. Fér.pl. 2. f. 6.

2. Griseo-rufus, fasciis nigris margine rufescente Fér. pl. S A, f. 2, 4.

3. Niger, fasciis lateralibus griseis.

4. Virescens, fasciis nigris.

5. Subrufus, fasciis nigris.

6. Griseus totus.

7. Griseus, fascia clypei et dorsi utrinque nigris.

Cet Arion, on ne peut plus commun, habite nos 
champs, nos bois et nos jardins, sous les pierres, la mousse et les feuilles mortes; il est encore très-commun dans nos chanticrs, sous les pièces de bois gisant sur le sol. Sa ponte a lieu dans les mois de Mai à Septembre; elle ne dépasse guère soixante-dix œufs ovales, blanchâtres, de deux millimètres et demi de long sur deux millimètres de large : ces œufs m'ont offert la particularité d'être phosphorescents pendant les quinze premiers jours de leur ponte; la lumière qu'ils produisaient élait assez vive les premiers jours; elle diminua, de jour en jour, jusqu'au quatorzième ou quinzième, qu'elle s'éteignit entièrement. Ges œufs éclosent au bout de vingt-quatre à qua rante jours; les petits sont adultes vers la fin de leur première année : comme ses congenères, cet Arion participe quelques mois avant à la reproduction de son espèce. La varièté $n^{\circ} 1$, bien que de la même longueur que la variété $\mathrm{n}^{\circ} 3$, c'est-à - dire longue de cinquante millimètres, est infiniment plus étroite : elle n'a que deux millimètres de largeur, tandis que la seconde en a quatre à cinq. Mucus jaune et très-épais.

Je ne cite point dans la synonymie de cette espèce les ourrages de MM. Brard, Grateloup, Michaud et Millet, parce qu'en parlant de cet Arion ces auteurs citent une Limacelle que le vrai Arion horlensis ne porte pas : ce qui me fait présumer que ce n'est point cet Arion qu'ils ont observé.

Genre Lima G, Limax. Lamarck.

Ni. 4. LIMACE CENDRÉE. Limax Cinereus.

Draparnaud, Loc. cit. p. $124, \mathrm{n}^{\bullet} 4, \mathrm{pl} .9$, f. 11.

Lamarck, Loc. cit. p. 50, n-3.

B lainville, Loc. cit. p. 430.

Brard, Loc. cit. p. 110.

3. 
Des Moulins, Loc, cit. p. 44, n·2.

Grateloup, Loc. cit. p. 5\%, n. 7.

Collard des Chorres, Loc. cit. p. 94, n. 3 .

Kick: $x$, Loc. cit. p. $6, n^{*} 6$.

Michaud, Loc. cit. p. $5, \mathrm{n} \cdot 2$ ?

Millet, Loc. cit. p. 116, n*4.

Bouillet, Loc. cit. p. 16, n・1.

Limax antiquorum. Férussac, Hist. Moll. p. 68, pl. 4, f. 1-8 et pl. 8, A, f. 1 .

Férussao, Supp. p. 96, d, n.1.

Limacella parma. Brard, Loc. cit. pl. 4, f. 1, 2, 9, et 10.

\section{VARIÉTÉS.}

1. Cinereus, clypeo maculis abdomine fasciis longitudinalibus nigris. Fér. pl. 4, f. 2,5 et $\%$.

2. Cinereus, Clipeo maculis abdomine fasciis interruptis nigris.

3. Albidus, clypeo maculis rotundatis nigris dorso seriebus punctis nigris quatuor. Fér. pl. 4, f. 8.

4. Cinereus, clypeo dorsoque maculis irregularibus nigris. Fer. var. g.

Habite les lieux voisins des habitations, dans les jardins, les cours des fermes, les chantiers et tous les autres lieux où elle peut s'abriter, sous les pièces de bois gisant sur le sol, particulièrement sous les vieux bois, dont elle fait une partie de sa nourriture. Enfin, elle est très-commune, et varie beaucoup dans la disposition de ses taches et de sa couleur; elle acquiert jusqu'à dix-sept et dix-huit centimètres de longueur, sur seize à dix-sept millimètres de largeur; son plan locomoleur est large de quatorze millimètres. C'estlaplus grande espèce de nos localités; elle est peu productive: je ne lui ai pas en corevu pondre plus de cinquante à soixante œufs; ils sont légèrement succinés, diaphanes, ovales, de cinq millimètres de diamètre longitudinal, et de quatre millimètres 'de diamètre transversal; ces œufs sont réunis en partie à leurs pôles par un prolongement deleur enveloppe externe, et forment ainsi des 
cspèces de chapelets de vingrt, de trunte el quelquefois de quarante œufs. Leur ponte a lieu de Juillet en Septembre; ils éclosent au bout de vingt-cinq à trente jours, el les petits sont adultes vers la fin de leur première annéc.

N. 5. IrmaCe TACHeT́E. Limax variegatus.

Draparnaud, Loc. cit. p. 127, n. 9.

Férussac, Hist. Moll. p. 71, pl. 5, f. 1-4.

Supp. p. $96, \mathrm{e}, \mathrm{n} \cdot 3$.

Tabl, syst. p. 21, n. 3.

Blainville, Dict. sc. nat. 1. 26, p. 430

Br ard, Loc. cit. p. 115.

Des Moutins, Loc. cit. p. 44, n-3.

Grateloup, Loc. cit. p. $56, \mathbf{n} 6$.

Kick $x$, Loc. cit. p. 6, n. 5 .

Michaud, Loc. cit. p. 6, n. 6 .

Millet, Loc. cit. p. 116, n.5.

Bouillet, Loc. cit. p. 17, n-9.

Limacella unguiculus. Brard, Loc. cit. pl. 4, f. 3, 4, 11 et 12 Férussac, pl. 5, f. 4.

\section{VARIÉTÉS.}

1. Luteurs aut succineus.. Fér. pl. 5, f. 1 .

2. Virescens aut rufus. Fér pl. 5, f, 2.

3. Flavescens. Fér. pl. 5, f. 3.

Habite les masures et les caves humides, ainsi que les lieux humides voisins des cuisines; on les voit le soir, quand il pleut, rechercher leur nourriture dans les immondices, et dérorer avec avidité les morceaux de pain et de légumes cuits, dont elles sont très - friandes. Je ne l'ai jamais trouvée dans les jardins, oủ Draparnaud dit qu'elle vit dans la France méridionale. Cette Limace est un peu moins grande que l'espèce qui précède, et avec laquelle elle a les plus grands rapports; elle n'est pas plus productive; sa ponte, qui a lieu d'Août en Novembre, ne dépasse pas soixante œufs, qui ne diffèrent de ceux de 
l'espèce citée qu'en ce qu'ils sont un peu plus gros; ils sont six semaines à deux mois à éclore, et les jeunes individus qui en proviennent n'alteignent leur dernier accroissement quà la fin de leur première année. Leur Mucus est incolore et assez épais. M. de Férussac n'a sans doute pas vu les œufs de cette Limace, puisqu'il lui attribue ceux du Limax agrestis, figurés dans sa planche 5, figure 5 .

Ces Limaces vivent en société; elles sont souvent réunies une douzaine dans le même trou, et placées les unes sur les autres; dans leurs moments de repos, elles ont presque toutes un de leurs tenlacules supérieurs à moitié déreloppé.

\section{N. 6. Lrmace des ARBRes. Limax arborum. Nob.}

Animal gélatineux, de couleur bleu-glauque, tirant quelquefois sur le vert, marqué irrégulièrement de petites taches ovalaires de diverses grandeurs, plus pâles que le corps : dos couvert de rides légèrement anastomosées, qui, lorsque l'animal rampe, forment des lignes longitudinales plus foncées que le corps; une bande blanchâtre d'environ un millimètre et demi de largeur prend naissance à l'extrémité postérieure du manteau, et va tout en diminuant et partageant le corps par son milieu jusqu’à son extrémité postérieure, qui est sensiblement carénée. Manteau arrondi à son extrémité antérieure, et terminé en pointe mousse, couvert de fines stries concentriques et vermicellées; orné de chaque côlé de deux bandes principales noires ou noirâtres, d'un millimètre et demi de largeur, bordées de deux autres bandes plus fines, très-claires ou jaunâtres; l'espace restant entre la dernière bande et le bord du manteau est marqué de petites taches semblables à celles disséminées sur le corps : ori- 
fice de la cavité pulmonaire silué au tiers postérieur du côté droit du m nteau, très-petit, arrondi et entouré d'un cercle noirâtre formé par la bande lon citudinale qui passe dessus. Tête grisâtre, translucide, coupée au milieu par deux pelits sillons longitudinaux qui s'étendent sur le cou; marquée de fines rides transversales, et bordée de chaque côté par une ligne plus foncée formée par le nerf rétracteur : tentacules inférieurs assez courts, deux millimètres; les supérieurs longs de dix millimètres et terminés par un petit mamelon, au centre duquel est un point noir, l'œil. Plan locomoteur blanchâtre, divisé en trois bandes longitudinales d'à-peu-près égale largeur; celle du milieu, le pied, entièrement translucide, laissant on ne peut mieux voir ses mouvements ondulatoires. Mucus incolore, trèsbrillant et peu abondant; mais lorsque l'on touche celte Limace, elle laisse échapper un liquiłe très-limpide et semblable à l'eau Ja plus pure.

Limacelle ovalaire, épaisse, très-blanche et nacrée en dessus, légèrement bombée en dessus, ornée de stries d'accroissement bien prononcées; dessous mat, plat et couvert de très-petits tubercules inégaux : appendices latéraux très-prononcés, donnant à la moitié antérieure, qui est beaucoup plus épaisse que le reste, un millimètre plus de largeur qu’à la moitié postérieure : celle-ci est large d'environ quatre millimètres, et la longueur totale est de sept à huit millimètres. La forme de cette Limacelle diffère de toutes celles décrites par Brard.

Habitesurles arbres, mais de préférence sur ceux qui sont vieux, couverts de mousse et dont une partie du bois est pourrie. Lorsque le temps est couvert ou pluvieux, on les voit ramper sur leur tronc et sur leurs branches, sous les écorces desquels elles se logent. Elle se nourrit de détritus de bois, et ne touche point aux feuilles; c'est du moins ce 
dont j'ai cru m'apercevoir en visitant et examinant avec la plus grande attention les arbres sur lesquels elle était très-commune, et où je n'ai trouvé aucune feuille entamée. Cette Limace multiplie fort peu; elle dépose vingt à trenie oufs sous les écorces ou dans les trous des vieux arbres, dans les mois de Septembre à Décembre. Ces œufs sont isolés, ovales, arrondis à leurs extrémités; ils ont quatre millimètres de longueur sur trois millimètres de largeur, et éclosent vers le trente -cinquième jour de leur ponte; les jeunes individus sont adultes vers la fin de leur première année; ils ont alors neuf à dix centimètres de longueur, dix millimètres de hauteur, huit à dix millimètres de largeur, et leur plan locomoteur a cinq à six millimètres de largeur. Ce sont, je pense, les jeunes indi-: vidus de cette Limace que Hoy, Shaw et Latham ont nommés Limax filans; je les ai vus bien des fois descendre d'une branche à l'autre, au moyen d'un mucus assez épais qu'ils filaient; ils paraissent craindre cette manière de voyager, car, lorsqu'ils n'ont plus que le tiers ou le quart postérieur de leur plan locomoteur fixé à la branche qu'ils veulent abandonner, ils dirigent pendant deux à trois minutes la partie antérieure de leur corps dans toutes les directions, conme pour chercher un point d'appui; n'en trouvant pas, ils commencent cette opération, penJant laquelle j’ai observé sur leur plan locomoteur, qui étaiı passablement rétréci, le même mouvement ondulatoire que l'on apercoit sur le pied d'une limace que l'on. fait ramper sur une plaque de verre.

\section{N. \%. Limacf agreste. Limax agreslis.}

Draparnaud, Loc. cit. p. 126. n. 7, pl. 9, f. 9.

Férussac, Hist. Moll. p. 73, pl. 5, f. 7-10.

$$
\text { Supp.p. } 96, \text { c, n } 6 .
$$


Blainville, Dict. sc. nat. t. 26, p. 430.

Brard, Loc. cit. p. 118.

Des Moulins, Loc. cit. p. 212, n. 1, vol. 3.

Grateloup, Loc. cit. p. $59, \mathrm{n} \cdot 8$.

Kickx, Loc. cit. p. 5, n- 4.

Michaud, Loc. cit. p. 6, n- 4.

Millet, Loc. cit. p. 117, n. 6.

Bouillet, Loc. cit. p. 17, n. 8 .

Limacella obliqua Brard, Loc. cit. pl. 4, f. 5, 6, 13, 14, 15.

Habile les champs, les falaises, les jardins; on ne peut plus commune dans ces diverses localités, assez rare dans nos bois. Je ne cile point de variétés de celte espèce, parce qu'elle est si variée dans sa coloration qu'on pourrait en faire une trop grande quantité ; j'en mentionnerai seulement une qui est si constante, que j'ai été tenté de l'élever au rang d'espèce; je l'ai constamment trouvée dans des lieux très - humides, et particulièrement sur les bords, couverts d'herbes, des ruisseaux. Elle est moitié plus petite que l'espèce principale; elle a environ trente millimètres de longueur, sur trois millimètres de largeur; son plan locomoteur n'a pas plus d'un millimètre et demi de large; elle est entièrement de couleur canelle, peu craintive et très-vive dans ses mouvements. Deux individus que j'ai conservés pendant plus d'un an chez moi, y ont pondu, du trente Mai au cinq Juin, soixante-trois œufs, l'un vingthuit et l'autre trente-cinq : ces œufs diffèrent aussi de ceux de l'espèce principale; ils sont ovales, translucides, longs d'un millimètre trois quarts, sur un millimètre un tiers de large; leur éclosion a eu lieu du vingt-quatre au trentième jour de leur ponte, et les jeunes individus, qui à cetle époque étaient de couleur vineuse, sont devenus, en grandissant, de la même couleur que leurs parents; enfin ces Limaces avaient atteint leur parfait développe. ment du vingt au trente Septembre, c'est-à dire à l'âge 
d'environ trois mois. L'espèce typique croît aussi trèsrapidement : j’ai vu des individus nés chez moi pondre le soixante-sixième jour de leur naissance, et n'avoir la taille adulte que le quatre-vingt-deuxième. Cette Limace multiplie beaucoup plus que ses congenères; elle commence ses pontes en Avril, et ne les termine qu'en Novembre. Deux individus ont pondu trois cent quatrevingt-huit œufs; c'est le nombre le plus élevé que j’aie observé; ordinairement leur ponte ne dépasse pas trois cents à trois cent cinquante œufs, qui sont toujours déposés par petits tas de trente à soixante-dix; ils sont globuleux, incolores, diaphanes, et ont deux millimètres de diamètre; ils sont dix-huit à trente jours à éclore. Cette Limace produit plusieurs générations dans la même année.

\section{N. 8. Limace brune. Limax brunneus.}

Draparnaud, Loc. cit. p. 128, n. 11.

Férussac, Hist. Moll. supp. p. 96, e, n 1.

Tabl. syst. p. 23, n. 1.

Blainville; Dict. sc. nat. t. 26, p. 432.

Habite dans les herbes qui garnissent les bords des ri. vières, des ruisseaux, les lieux très-humides, sous la mousse, sous les pierres situées près des sources de nos falaises : assez commune.

Gette Limace est la moins productive de celles de notre pays; elle met six à huit jours à effectuer sa ponte, qui ne se compose que de donze à dix-huit œufs, déposés par deux, trois ou quatre au plus, et entre chaque dépôt desquels elle met un intervalle d'au moins vingt-quatre heures. Comme ses congenères, elle dépose ses œufs la nuit : ceux - ci sont ovales - arrondis, d'un millimètre un quart de long, sur un millimètre de large; ils sont incolores et aussi transparents que le cristal; leur éclosion a 
lieu du trentième au quarantième jour de leur ponte, et les petits, au sortir de l'œuf, ont environ trois millimètres; ils sont rougeâtres, et brunissent de jour en jour jusqu'à l'état adulte, qu'ils atteignent. vers le soixantedixième jour de leur naissance : alors ils sont entièrement, même le plan locomoteur, de couleur brun-carmélite : ce qui a fait dire à Draparnaud et à divers autres auteurs, que l'extrẻmité postérieure de son manteau était jaunâtre; c'est la transparence de ce même manteau qui laisse trèsdistinctement voir la coquille interne; il est couvert de fines stries concentriques, et est percé vers le tiers postérieur, du côté droit, pour l'ouverture de la cavité pulmonaire, qui est arrondie. La tête, aussi brune que le corps, porte quatre tentacules de même couleur, dont les deux supérieurs ont deux millimètres de longueur, et les deux inférieurs ont à peine un millimètre; le corps est long de vingt millimètres, large vers son milieu de deux millimètres, et son plan locomoteur est large d'un millimètre; son mucus est incolore et très-liquide.

La description, ainsi que les figures de la Limacella concava de Brard, conviennent parfaitement à celle de celte espèce, qui seulement est assez épaisse, non transparente, mais bien translucide.

Cette petite Limace est peu craintive et très-vive dans ses mouvements; elle a les plus grands rapports de forme avec ma variété couleur canelle du Limax agrestis.

Genre Vitrine. Vitrina Draparnaud.

N. 9. Vitrine transp a ente. Vilrina pelluoida.

Draparnaud, Loc. cit. p. 119, pl. 8, f. 34-3\%.

Férussac, Hist. Moll. pl. 9, f. 5.

Lamarck, Loc cit. p. $53, \mathrm{n} \cdot 1$. 
Brard, Loc. cit. p. 78, pl. 3, f. 3-6.

Des Moulins, Loc. cit, p. $45, \mathrm{n} \cdot 1$.

Grateloup, Loc. cit. p. 62.

Collard-des-Cherres, Loc. cit. p. 95, n 1.

Michaud, Loc. cit. p. 9, n-1.

Millet, Loc. eit. p. 117, n. 8 .

Bouillet, Loc. cit. p. 21, n· 12.

Habite sous les pierres, les feuilles mortes et le détritus des plantes de nosbois, de nos haies, et des dunes du Châtillon, où elle est particulièrement très-commune; là, pendant les chaleurs diurnes, elle s'enfonce dans le sable; elle ne dépose ses œufs qu'en Septembre, Octobre ou Novembre; ils sont globuleux; isolés et entièrement hyalins; ils ont environ deux tiers de millimètre de diamètre, et sont réunis en petits paquets de huit à quinze, par une couche de matière albumineuse, aussi incolore, qui les fixe sous les pierres des lieux bas et humides, ou dans le détritus des plantes; ils éclosent quinze à vingt jours après leur ponte, et les petits, qui sont rougeâtres au sortir de l'œuf, deviennent gris en grossissant, et atteignent leur état parfait vers leur huitième ou dixième mois.

Je crois que ces mollusques ne vivent pas plus d'un an à quinze mois, parce quue, dans le mois de Janvier, j’ai toujours trouvé sous les pierres de nos dunes, où, comme je l'ai déjà dit, ils sont très-communs, une grande quantilé d'individus adultes morts, chez lesquels la putréfaction commençait à s'opérer, et d'autres languissants, fixés sous ces pierres, et entièrement rentrés dans leur coquille : ils mourraient donc quelque temps après d'avoir effeclué leur ponte. 


\section{ORDRE II. \\ TRACHELIPODES. Lamarck.}

\section{Genre Hélice. Helix. Linné.}

N. 10. Helice variable. Helix variabilis.

Draparnaud, Loc. cit. p. 84, , n. 12 , pl. 5, f. 11, 12.

Ferussac, Tabl. syst. p. 44, n-284.

Lumarck, Loc. cit, p. 83, n・65.

Payraudeau, Mollusques de l'île de Corse, p. 99, n. 202.

Des Moulins, Loc. cit. p. 45, n- 1.

Grateloup, I.oc. cit. p. $9 S, \mathrm{n} \cdot 6$.

Collard des-Cherres, Loc. cit. p. $96, \mathrm{n} \cdot 5$.

Michaud, Lnc. cit. p. 16, n' 14.

Hetix Virgata, Maton ct Backett, Transaction of the Linnean Society, t. 8, p. 195, n. 13.

Turton, Conchological Dictionary of the British Islands, p. $50, n \cdot 14$.

\section{VARIÉTÉS.}

1. Multifasciata. Drap. a.

2. Bifasciata. Drap. b.

3. Tessellata. Drap, c:

4. Albicans. Grat. 4.

5. Omnino alba. Drap. d.

6. Alba, hyalozona.

7. Omnino grisea.

\section{Monstrum.}

Conico-turrita.

Habite les lieux arides et sablonneux; très-commune dans les dunes du Châtillon, où elle offre plusieurs belles variétés. Celles de nos falaises sont moitié plus petites que celles de nos dunes. Ces animaux sont fort peu sensibles au froid et n'hibernent pas; quand il gôle ou que le gazon est couvert de neige, ils forment un épiphragme vitreux, comme celui qu'ils construisent journellement dans la saison des chaleurs pour s'abriter des rayons solaires; 
aussitôt que le dégêle a lieu, on les voit de nouveau ramper et rechercher leur nourriture. Ils font leur ponte depuis Septembre jusqu'en Janvier, mais le plus ordinairement de Septembre en Novembre; elle se compose de quarante à soixante œufs globuleux, blancs opaques, d'un millimètre et demi de diamètre; ces œufs sont déposés dans le sable ou en terre, et éclosent du quinzième au vingtième jour de leur ponte; pendant les deux ou trois premiers mois de leur naissance, leur coquille est couleur de corne; ils n'atteignent leur dernier degré d'accroissement que dans le cours de leur seconde année, mais participent à la reproduction de leur espèce vers la fin de la première. Ces mollusques varient de couleur, comme leur coquille; plus celle-ci est blanche, plus l'animal est noir; en sorte que la variété $\mathrm{n}^{\circ} 6$, qui est blanche avec des bandes hyalines, offre ces bandes comme noires lorsque l'animal habite sa coquille.

N. 11. Hélice vigneronne. Helix pomatia.

Draparnaud, Loc. cit. p. 87, n- 15. pl. 5. f. 20-22.

Férussac, Tabl. syst. p. 29, n· 31.

Hist. Moll. pl. 21 et pl. 24, f. 2.

Lamarck, Loc. cit. p. 67, n. 8.

Blainville, Dict. sc. nat. t. 20, p. 424, n. 11 .

Maton et Rackelt, Loc. cit. p. 201, n. 24.

Brard, Loc. cit. p. 28, n• 31.

Turlon, Loc. cit. p. 56, n・ 26.

Kickx, Loc. cit. p. 28, n• 31.

Michaud, Loc. cit. p. 118, n- 12.

Bouillet, Loc. cit. p. 28, n· 19.

IIabite sous les haies et dans les bois, plus commune dans cette dernière localité; sa ponte a lieu dans les mois de Juin à Septembre, et se compose de soixante à quatre. vingts œufs globuleux, blanc-verdâtre et opaques; ils ont six millimètres de diamètre, et éclosent au bout de vingt 
à trente jours. Les petits deviennent adultes vers la fin de leur promière année; pendant cette première année, leur coquille est couverte d'un épiderme fauve, qu'elle perd en vieillissant; lors de leur hibernation, ils construisent un épiphragme très - solide, gris, opaque et calcaire. La forêt de Boulogne produit une variśté dont les tours de spire sont plus élancés qu'ils ne le sont ordinairement.

N. 12. Helige porphyre. Helix arbustorum.

Draparnaud, Loc. cit. p. 88, n-16, pl. 5, f. 18.

Férussac, Hist. Moll. pl. 27, f. 5-8, pl. 29, f.1-3.

Tabl. syst. p. 30, n・ 40.

Lamarck, Loc. cit. p. $80, n \cdot 56$.

Bla inville, Dict. sc. nat. t. 20, p. 425, n* 14.

Maton et Rackett, Loc. cit. p. 202, n-25.

Brard Loc. cit. p. 65, pI. 2, f. 12.

Turton, Loc. cit. p. $56, \mathrm{n} \cdot 2 \%$.

Kick: $x$, Loc. cit. p. 30, n: 33.

Michaud, Loc. cit. p. 1\%, n. 18 .

Millet, Loc. cit. p. 119, n- 13.

Bouillet, I.oc. cit. p. $29, \mathrm{n} \cdot 20$.

Habite les lieux très-humides et ombragés, sur le gazon et les haies qui bordent les ruisseaux et les rivières', dans les bois; très-commune; sa ponte a lieu dans les mois de Juillet à Septembre; elle est de trente à cinquante oufs arrondis, jaunâtres, opaques, d'environ trois millimètres de diamètre; ils éclosent au bout de quinze à vingt jours, et les individus qui en proviennent sont adultes quinze à seize mois après.

N- 13. Helice chagrinée. Ilelix aspersa.

Draparnaud, Loc. cit. p. 89, n. 18, pl. 5, f. 23.

Férussac, Tabl. syst. p. $30, \mathrm{n}^{-5} \mathbf{5 1}$.

Hist. Moll. pl. 18, f. 1-11, et pl. 24, f. 3.

Lamarck, Loc cit. p: 68, n. 9.

Blainville, Loc. cit.p. 422. n 6.

Brard, Loc, cit. p. 7, pl. 4, f. 1. 
Payraudeau, Loc. cit. p. 97, n- 193.

Des Moulins, Loc. cit. p. 46, n- 3 .

Grateloup, Loc. cit. p. $89, \mathrm{n} \cdot 1$.

Collari-des-Cherres, Loc, cit. p. 93, n・1.

Kichix, Loc. cit. p. 29, n• 32.

Michaud, Loc. cit. p. 17. n' 20.

Millet, Loc. cit, p. 119, n- 14.

Bouillel, Loc. cit. p. 30, n-21.

Hetiox horlensis. Maton et Rackett, Loc. cit. p. 208, n-39.

Turton, Loc. cit. p. 60, n. 41.

\section{Monstrum.}

1. Semiscalaris.

2. Scalaris. Fér. pl. 19, f. 3. (1)

Habite les bois, les champs, les jardins, les haies, les dunes, etc. ; enfin, elle est on ne peut plus commune, et variée dans sa coloration et dans sa grosseur; nos dunes en nourrissent une jolie petite variété, qui est moins grosse que l'Hélix hortensis ordinaire. Ce mollusque est, je crois, celui qui multiplie le plus parmi ses congenères : j’ai compté plusieurs fois cent et cent dix œufs pondus par un seul individu; ils sont ovales, d'un blanc verdâtre, opaques; ils ont quatre millimètres de diamètre longitudinal, sur trois millimètres et demi de diamètre transversal : ces œufs sont déposés de Mai en Octobre, et leur éclosion varie, suivant la saison, de quinze jours à un mois; les jeunes individus deviennent adultes dans les premiers mois de leur seconde année; ils sont trèssensibles au froid, et hibernent de bonne heure; ils construisent jusqu’à six ou huit épiphragmes très-minces, cornés, verdâtres, réunis ou séparẻs.

(1) Les monstruosités scalaris des Helix aspersa et horlensis ont été trouvées dans les jardins de MM. Leducq, D. M. et Charles Dernarle, de Boulogne, qui ont eu la bonté de me les effrir; jè prie ici ces Messieurs d'en agréer mes bien vifs remercînents. 
N. 14. Hélices Némorale. Helix nemoralis.

Draparnaud, Loc. cit. p• 94, n·22, pl. 6. f.3-5.

Férussac, Tabl. syst. p. 31, n. 56.

Hist. Moll. pl. 33, 34 et pl. 39 A, f, 3, 4 .

Lamarck, Loc. cit. p. 81, n* 58.

Blainville, Dict. sc. nat. t. 20, p. 423, n- 8 .

Maton et Rackett, Loc. cit. p. 206, n• 38.

Brard, Loc. cit. p. 12, pl. 1, f. 2, 4.

Turton, Loc. cit. p. $59 . \mathrm{n} \cdot 40$.

Payraudeau, Loc. cit. p. 98, n· 199.

Des Moulins, Loc. cit. 6, p. 46, n• 4 .

Grateloup, Loc. cit.p. 91, n· 3 .

Collard-des-Cherres, Loc. cit. p. 95, n-2.

Kick $x$, Loc. cit. p. 27, n* 30.

Michaud, Ioc. cit. p. 18, n' 25.

Millet, Loc. cit. p. 120, n· 15.

Bauillet, Loc. cit. p. 30, n-22.

\section{VARIÉTÉS.}

\section{Non fasciata.}

1. Lutea tota. Drap. c. Fér. pl. 33, f. 5.

2. Lutea subincarnata. Drap. 1.

3. Omninò incarnata. Drap. m-

4. Rufa. Drap. r.

5. Castanea aut subfusca. Drap. s.

Unifasciati.

6. Lutea unifasciata. Drap. Ł. Fér. pl. 33, f. 6.

7. Luteo-incarnata unifasciata.

8. Incarnata unifasciata. Drap. $n$.

9. Rufa unifasciata.

\section{Bifasciala.}

10. Lutea, 2 fasc. fuscis latissim. Drap. a. Fér. pl. 33, f. 9.

11. Lutea, 2 fasc. interius continuatis. Drap. e. Fér. pl. 33, f. 10.

12. Incarnata, 2 fasc. extrinsecus continuatis.

13. Incarnata, 2 fasc. lutea et fusca.

\section{Trifasciala.}

14. Lutea, 3 fasc. latis, superıoribus continuatis. Drap. b.Fér.pl.33,f.12.

15. Lutea 3 fasc. infima latissima. Drap. g. Fér. pl. 34, f. 6. 
16. Lutea, 3 fasc. suprema augustissima. Drap: d.

17. Incarnata, 3 fasc. infimâ latissima, superioribus duabus continuatis.

18. Incarnata, 3 fasc. infimâ augustissima superioribus, duabus continuatis.

19. Incarnata, 3 fasc. superiori extrinsecùs continuata.

\section{Quadrifasciata.}

20. Lutea, 4 fasc. superioribus duabus continuitis. Drap. e. Fér. pl. 33, f. 15 .

21. Lutea, fasciis quatuor inæqualibus.

22. Incarnata, fasciis quatuor. Mill. $r$.

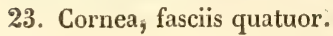

\section{Quinquefasciata.}

24. Lutea, fasciis quinque. Drap. z. Fér. pl. 33, f. 16, et pl. 34, f.10,11. 25. Incarnata, fasciis quinque. Mill. s.

Habite les champs, les jardins, les bois, les falaises, les dunes et sur les haies; très-commune. Les individus qui viyent dans nos falaises sont presque une fois aussi gros que les autres; ils ont tous les organes de la génération, noirs. Cette hélice dépose ses œufs, au nombre de cinquante à quatre-vingts, dans les mois de Mai à Octobre; ils sont ovales arrondis, jaunâtres, opaques, d'environ trois millimètres de diamètre. Les petits éclosent du quinzième au vingtième jour, et sont adultes vers la fin de leur première année, ou dans les premiers mois de la suivante.

N. 15. Hélice des JaRdins. Helixhortensis.

Draparnaud, Loc. cit. p. 95, n. 23, pl. 6, f. 6.

Férussac, Tabl. syst. p. 31, n. $5 \%$.

Hist. Moll. pl. 35 et 36 .

Lamarck, Loc. cit. p. 81, n· 59.

Blainvillo, Dict. sç. nat. t. 20, p. 423, n' 9.

Brard, Loc. cit. p. 15, pl. 1, f. 3 :

Des Moùlins, Loc. cit. p. 47, n. 5.

Grateloup, Loc. cit. p. 94, n- 4.

Collard-des-Cherres, Loc cit. p. 96, $\mathrm{n} 3$.

Kickz, Loc. cii. p. 26, n. 29. 
Michaud, Loc. cit. p. 19 , n. 26.

Millet, Loc. cit. p. 121, n· 16.

Bouillet, Loc. cit. p. 32, n· 23.

Helix nemoralis, Maton et Rackett, Loc. cit. p. 206, n. 38.

Turton, Loc. cit. p. $59, \mathrm{n} \cdot 40$.

\section{VARIETES。}

\section{Non fasciala.}

1. Omnino lutea. Drap. d. Fér. pl. 35, f. 1.

2. Lutea, labro fusco. Grat. 6.

3. Albida, Grat. 3.

4. Cornea.

5. Cornea subfusca. Drap. e.

6. Incarnata, Grat. 2. Fér. pl. 36, f. 1, 7 et 8.

\section{Unifasciata.}

7. Lutea, unifasciata. Drap. g. Fér. pl. 36, f. 4.

8. Lutea, fascia latissima. Fér. pl. 36, f. 5.

9. Incarnata, unifasciata. Drap. e.

10. Cornea, unifasciata.

\section{Bifasciata.}

11. Albida, fasciis pellucidis.

12. Lutea, fasciis fuscis.

13. Lutea, fasciis fuscis labro roseo. Grat. 12.

\section{Trifasciala.}

14. Albida, fasciis pellucidis.

15. Lutea, fasciis æqualibus fuscis. Fér. pl. 35, f. 9 ;

16. Lutea, fascis inæqualibus fuscis. Grat. 14.

17. Lutea, fasciis griseis.

18. Lutea, fasciis fuscis labro roseo.

\section{Cuadrifasciata.}

19. Albida, fasciis pellucidis.

20. Lutea, fusciis fus is. Grat. 15, Fér. pl. 36, f. 6.

21. Lutea, fasciis fuscis interruptis. Grat. 16.

22. Lutea, fasciis fuscis, labro fusco.

23. Rosea, fasciis pellucidis.

\section{Quinquefasciata.}

24. Lutea fasciis fuscis. Drap. a. Fér.pl, 35, f. 11. 
25. Iutca, fasciis fuscis, labro roseo.

26. Lutea, fasciis fuscis interruptis. Drap. b.

27. Lutea, fasciis fuscis.

Sex/asciata.

Sepiemfasciata.

28. Lutea, fasciis fuscis.

Lutea, scalaris.

\section{Monstrum.}

Habite les champs, sur les haies, les bois, les jardins et les dunes; partout très-commune, et très-variée dans sa coloration; sa ponte a lieu dans la même saison que celle de l'espèce qui précède; elle se compose aussi d'àpeu-près le même nombre d'oufs, el ceux-ci sont seulement un peu plus petits; leur éclosion, ainsi que le développement des jeunes individus, s'opèrent dans le même espace de temps. J'ai remarqué que dans les dunes habitées par l'Helix hortensis se trouvait aussi l'Helix variabilis, avec laquelle clle vit sur le gazon; et que dans celles où se trouve l'Helix nemoralis, celle-ci est toujours accompagnée de l'Helix ericetorum; mais que jamais on ne voit, dans ces sortes de localités, l'une des deux premières espèces vivre avec l'une des deux dernières.

N. 16. Hélice bimarginée. Helix carthusianella.

Draparnaud. Loc. cit. p. 101, n• 30, pl. 6, f. 31, 32.

F érussac, Tabl. syst. p. 43. n· $25 \%$.

Lamarck, Loc. cit. p. 85, n· 71 .

Blainville, Dict. sc. nat. t. 20, p. 431, n. 32.

Des Moulins, Loc. cit. p. 47, n' 9.

Graletoup, Loc. cit. p. 101, n· 9.

Kickx, Loc. cit. p. 25, n- 28.

Michaud, Loc. cit. p. 25, n' 38.

Mrllet, loc. cit. p. $122, \mathrm{n} \cdot 18$.

Commune dans toutes nos prairies, sur les plantes herbacées. Celte IIélice, moilié plus petite que l'Helix nchehusiana, arec laquelle elle a quelques rapports, pond 
des œufs presque aussi gros que les siens; ils sont globuleux, opalins, et ont un millimètre un quart de diamètre; chaque ponte se compose de soixante à quatre-vingts œufs, qui éclosent du treizième au quinzième jour de leur ponte, et les petits atteignent leur dernier degré d'ac-croissement vers la fin de leur première année.

N. 17. Hélice d'olivier. Helix olivieri.

Firussac, Tall. syst. p. 43, n• 255, var. g.

Michared, Lọc. cit. p. 25, 39.

II. Carthusianella v, b. Draparnaud, Loc. cit. p. 101, n-30, pl. \%, f. 3, 4.

Grateloup, Loc. cit. p. 101, n. 93.

Millet, Loc. cit. p 122, n・ 18.

Habite les pelouses sèches voisines des dunes de Condette. Je ne pense pas que celle Ilélice doive être séparée de la précédente, dont elle ze diffère qu'en ce qu'elle a la coquille plus petite, plus mince et un peu plus conique; du reste, ses habiludes et sa ponte sont alssolument les mêmes.

N. 18. Hélice chartreuse. Helix carthusiana.

Draparnaud, Loc cit. p. 102, n· 31, pl. 6, f. 33.

Férussac, Tabl. syst. p. 43, n. 258.

Lawarck, Loc. cit. p. 85, n· 72.

Blainville, Loc. cit., t. 20, p. 431, n. 34 .

Brard, Loc. cit. p. 24, pl. 1, f. 6, $\%$.

Payraudeau, Loc. cit. p. 100, n. 206.

Grateloup, Loc. cit. p. 100, n. 8 .

Michaud, Loc cit. p. $26, \mathrm{n} \cdot 40$.

H. Cantiana. Maton et Rackett, Loc. cit. p. 19\%, n-16.

Turton, Loc. cit. p. 5\%, n. $1 \%$.

Férussac, Tabl. syst. p. 43, n.264.

Habile les prairies et les digues de la Liane, où elle cst très-commune sur les plantes herbacées, plus rare sur le gazon des boŕds des ruisseaux de certaines de nos Dunes et dans les fossés de nos grandes routes. Celle 
espècs, dont la coquille est ordinairement blanchâtre, offre une variété dont le dernier tour de spire est rougeâtre. Elle choisit pour le dépôt de ses œufs les endroits les plus humides des lieux qu'elle habite; il a lieu, comme chez les deux espèces précédentes, de Juillet en Septembre, et se compose de soixante à quatre-vingt-dix œufs globuleux, opalins, qui ont un millimètre et demi de diamètre; ils éclosent au bout de quatorze à quinze jours, et les petits atteignent leur parfait développement vers la fin de leur première année; mais ils participent à leur reproduction long-temps avant et lorsque leur cnquille est encore si fragile, que, le plus ordinairement, elle en est endommagée. Hiberne de Novembre en Février, et forme un épiphragme vitreux.

N- 19. Hélice pubescente. Helix sericea.

Draparnaud, Loc. cit. p. 103, n. 33, pl. 7, f. $16,1 \%$.

Firussac, Tabl. syst. p. 44, n·272.

Des Moulins, Loc. cit. p. $48, \mathrm{n} \cdot 11$.

Blainville, Loc. cit. t. 20 , p. 435.

Grateloup, Loc. cit. p. 118, n' 29.

Collard-des-Cherres, Loc. cit. p. 9\%, n. 15.

Michaud, Loc. cit. p. 27, n· 43.

Millet, Loc. cit. p. $122, \mathrm{n} \cdot 19$.

Habite les jardins, le long des murs, sous les pierres de nos falaises et sous celles gisant près des habitations champêtres. Ses œufs, leur éclosion et le développement des petits sont absolument les mêmes que chez l'Helix hispida.

N. 20. Hélice révéLée. Helix revelala.

Férussac, Tabl. syst.p. 44, n. 273.

Michaud, Loc. cit. p. 27, n.44, pl.15, f. 6,8 .

Animal allongé, légèrement ridé, grisâtre au-dessus du corps; cốés et plan locomotcur jaunâtre; tête et tentacules noirâtres; cou orné de chaque côté d'une petite 
bande noirâtre, formée par le muscle rétracteur des tentacules supérieurs : ceux - ci lon „s, grêles; les inférieurs obtus et courts, environ le tiers des supérieurs. Manteau jaunâtre; plan locomoleur très-étroit, terminé postérieurement en pointe. Habile dans nos bois, sur les jeunes Aulnes de deux ou trois ans; elle passe la belle saison sur les feuilles de ces jeunes arbres; le jour, pour se mettre à l'abri des rayons solaires, elle reste fixée sous ces mêmes feuilles, dont elle fait sa nourriture, tombe avec elles vers les mois de Septembre et d'Octobre, et s'occupe alors de sa reproduction, qu'elle abrite encore de ces feuilles mortes; ses œufs, au nombre de quarante à cinquante, sont sphériques et opalins; ils ont un millimètre de diamètre; leur éclosion a lieu vers le vingtième jour de leur ponte, et ils sont adultes au bout de dix à douze mois. Commune.

N. 21. Hélice hispide. Helix hispida.

Draparnaud, Loc. cit. p. 103 , n' 35, pl. 8, f. 20-22.

Férussac, Tabl. syst. p. 44, n· 271.

Lamarck, Loc. cit. p. 92, n· 100.

Blainville, Dict. sc. nat. t. 20, p. 436.

Maton et Rackett, Loc. cit. p. 198, n-18.

Brard, Loc. cit. p. 27, pl. 2, f. 1.

Turton, Loc. cit. p. 53, n- 19.

Des Moulins, loc. cit. p. 48, n. 12.

Grateloup, Loc. cit. p. 117, n. 28.

Collard-des-Cherres, Loc. cit. p. 9\%, n- 10.

Kick $x$, Loc. cit. p. 22, n. 25.

Michaud, Loc. cit. p. 28, n. 45.

Millet, Loc. cit. p. $123, \mathrm{n} \cdot 21$.

Bouillet, Loc. cit. p. 34, n. 25.

\section{VARIÉTÉS.}

1. Subrufa, solidior. Drap. b.

2. Albida, peristomate marginato. Drap. g.

Habite les champs, les bois, les jardins, les falaises, elc. 
Très-commune sous les pierres, sous les mousses el sur les orlies. Eille dépose, dans les mois d'Avril à Septembre, une quarantaine d'œufs globuleux, blancs et opaques, d'environ un millimètre de diamètre; ils éclosent du vingt au vingt-cinquième jour de leur ponte; au sortir de l'œuf, la coquille du jeune individu est déjà cornée; ; elle a à-peuprès un tour de spire, et plus de la moitié de ce tour de spire est couverle de petils poils roux, droils, et d'autant plus forts, qu'ils approchent du péristome: ils ne sont adultes qu'à l'âge de quinze à seize mois.

N. 22. Hélice roussatre. Helix rufescens.

Maton et Rackett, Loc. cit. p. 19\%, n. 15.

Turton, Loc. cit. p. 52, n. 16 .

Férussac, Tabl. syst.p. 44, n. 270.

H. Altenana. Kickx, Loc. cit. p. 23, n. 26, f. 4, 5.

\section{VARIÉTÉS.}

1. Alba.

2. Subcornea.

3. Cornea.

4. Rubens.

Animal jaunâtre, gुris, brun ou noir; très-chagriné. Tête et tentacules de même couleur que le corps; tentacules supérieurs très-grêles, longs de cinq millimètres ; les inférieurs très-courts, un millimètre et demi; plan locomoteur de même couleur, mais un peu moins foncé que le corps. Longueur, seize millimètres; largeur, deux millimètres. Sa ponte se compose de quarante à cinquante ceufs globuleux, opalins, d'environ un millimètre et demi de diamètre; elle a lieu dans les mois d'Août à Octobre; les petits éclosent au bout de vingt à vingt-cinq jours, et sont parvenus à l'état parfait vers la fin de leur première année, ou dans ies premiers mois de leur seconde.

Coquille subdéprimée, légèrement convere en dossus, 
carénée, et marquée sur la carène d'une pelite bande blanche, qui s'aperçoit même dans la variélé de celte couleur; elle est ornée de stries très-fines et serrées. Ordinairement de couleur roussâtre, mais quelquefois entièrement blanche, cornée ou rougeâtre; assez mince, et translucide. Six tours de spire, ouverture ovalaire, péristome évasé, tranchant, garni intérieurement d'un bourrelet blanc; ombilic assez large, laissant voir le sommet de la spire, Largeur, treize millimètres; hautcur, sept millimètres.

Habile nos champs, sur le gazon, sur les buissous, sous les pierres; dans nos jardins, sur les fraisiers; dans nos chantiers, sous les pièces de bois gissant sur le sol. On ne peut plus commune. - Je conserve à cette espèce le nom qui lui a été donné par les auteurs anglais, parce qu'il est antérieur à celui d'Altenana, donné par les Allemands.

N. 23. Hélice internompde. Helix intersecta.

Lamarek, Loc. cit. p. $85, \mathrm{n} \cdot 70$.

Brard, Loc. cit. p. 39, pl. 2, f. 7.

Grateloup, Loc. cit. p. 10\%, n. 16.

Michaud, Loc. cit. p. 30, n· 50.

Bouillet, Loc. cit. p. $35, \mathrm{n} \cdot 2 \%$.

H. Striata. Draparnaud, Loc. cit. p. 106, n-39, var. b, d.

Firussac, Tabl. syst. p. 44, n. 278.

Kickx, Loc. cit. p. $21, \mathrm{n} \cdot 23$.

H. Caperata. Maton el Rachell, Loc, cit. p. 196, n· 14.

Turton, Loc, cit. p. $51, \mathrm{n} \cdot 15$.

IIabite toutes nos pelouses arides, nos falaises et le voisinage de nos dunes, dans lesquelles on la trouve aussi, mais plus rarement; très-commune. Elle vit partout avec l'Helix striata, dont elle n'est qu'une variété; leurs animaux et leur reproduction sont absolument les mêmes, et j'ai observé très-souvent les premiers accouplés en semble; leur ponte a lieu depuis Aoûl jusqu'en Octobro 
elle est de trente-cinq à quarante œufs globuleux, trèsblancs, opaques, et d'environ trois-quarts de millimètre de diamètre; ils éclosent vers le quinzième ou vingtième jour de leur ponte, et sont adultes à la fin de leur première année : ils varient de couleur, du gris-clair au noir le plus intense, et sont fortement ridés.

N·24. HÉlice STRIÉE. Helix striala.

Draparnaud, Loc. cit. p. $106, \mathrm{n} \cdot 39$, pl. 6, f. 18-20.

Lamarck, Loc. 6, p. $93, \mathrm{n} \cdot 103$.

Brard, Loc. cit. p. 36 , pl. 2, f. 5, 6.

Payraudeau, Loc. cit. p. 101, n. 213.

Blainville, Loc. cit. t. 20, p. 433.

Des Moutins, Loc. cit. p. 48, n· 13.

Grateloup, Loc. cit. p. 105, n. 15.

Collard-des-Cherres, Loc. cit. p. 9\%, n-12.

Michaud, Loc. cit. p. $32, \mathrm{n} \cdot 51$.

Millet, Loc. cit. p. $123, \mathrm{n} \cdot 22$.

Bouillet, Loc. cit. p. $34, \mathrm{n} \cdot 26$.

H. thimorum. Kickx, Loc. cit. p. 20, n.22.

Habite arec la précédente, qui n'en est, comme je l'ai dit, qu'une variété.

N. 25. Hélice ruban, Helix ericetorum.

Draparnaud, Lec. cit. p. 107, n. 40 , pl. 6, f. 12.

Férussae, Tabl. syst. p. 44, n· 201.

Lamarch, Loc. cit. p. 84, n. 69.

Blainville, Dict. sc. nat. t. 20 , p. 434.

Maton et Rackett, Loc. cit. p. 194, n-11.

Brard, Loc. cit. p. 45 , pl. 2 , f. 8.

Turlon, Loc. cit. p. 49, n. 12.

Payraudeau, Loc. cit. p. 100, n· 205.

Des Moutins, Loc. cit. p. $48, \mathbf{n} \cdot 14$.

Grateloup, Loc. cit. p. 114, n. 25.

Collard-des-Cherres, Loc. cit. p. 96, n. $\%$

Kicks, Loc. cit. p. 18, n· 20.

Michaud, Loc. cit. p. $34, \mathbf{n} \cdot 54$.

Millet, Loc. cit. p. 124, n. 24.

Bouillet, Loc. cit. p. 36, n. 29. 


\section{VARIÉTÉS.}

1. Alba. Drap. g.

2. Unifasciata.

3. Bifasciata. Grat. 2.

4. Trifasciata.Grat. 3.

5. Quadrifasciata. Grat. 4.

6. Quinquefasciata. Grat. 5.

7. Fasciis oblitteratis. Drap. 6.

Habite nos pelouses et côteaux arides, les falaises et les dunes; très-commune. Elle pond, dans les mois d'Août à Novembre, quarante à soixante œufs d'un millimètre et demi de diamètre, sphériques et blanc-mât; leur éclosion a lieu le vingtième jour, et les jeunes individus atteignent leur parfait développement vers le milieu de leur seconde année.

N. 26. Hélice mignonne. Helix pulchella.

Draparnaud, Loc. cit. p. 112, n-49, pl. 7, f. 30-34.

Férussac, Tabl. syst. p. 39 ; n 173.

Lamarck, Loc. cit. p. 94, n. 107.

Biainville, Dict. sc. nat. t. 20 , p. 429 , n 29.

Brard, Loc. cit. p. 56, pl. 2, f. 9.

Payraudzau, Loc. cit. p. 102, n-218.

Des Moulins, Loc. cit. p. $49, \mathbf{n} \cdot 18$.

Graleloup, Loc. cit. p. $168, \mathrm{n} \cdot 18$.

Collard-des-Cherres, Los. cit. p. 97, n-14.

Kick $x$, Loc. cit. p. 13, 14, n-13, 14.

Michaud, Loc. cit. p. $42, \mathrm{n} \cdot 69$.

Millet, Loc. cit. p. $125, \mathrm{n} \cdot 2 \mathrm{~S}$.

Bouillet, Loc. cit. p. $39, \mathrm{n} \cdot 34$.

H. palulosa. Maton et Rackelt, Loc. cit. p. 193, n·10, pl. 5., f. 5.

Turbo paludosus. Turton, Loc. cit. p. $228, \mathrm{n} \cdot \mathrm{S9}$.

Habite les bords des mares, ruisseaux et rivières, dans les herbes, sous les pierres des lieux très-humides de nos champs, de nos fillaises et de nos dunes; très - commune. Elle pond dans les mois d'Août et de Septembre, douze 


\section{0}

à vingt petits œufs globuleux et opalins, qui ont à peinc un demi-millimètre de diamètre; le petit tas formé par leur réunion est souvent deux ou trois fois aussi gros que l'animal et sa coquille. Les pelits éclosent au bout de quinze à vingt jours, et sont adultes vers la fin de leur première année.

N. 2\%. Hélice bouton. Heitix rolundata.

Draparnaud, Loc. cit. p. 114, n' 52 , pl. 8 , f. 4-7.

Férussac, Tabl. syst. p. $40, \mathrm{n} \cdot 196$.

Lamarck, Loc. cit. p. $92, \mathrm{n} \cdot 101$.

Blainville; Loc. cit. t. 20, p. 433.

Brarı, Loc. cit. p. 51, n. 11, pl. 2, f. $10,11$.

Des Moutins, I.oc, cit. p. 49 , n* 19.

Graleloup, Loc. cit. p. $104, \mathrm{n} \cdot 14$.

Collard-des-Cherres, Loc. cit. p. 97, n. 11.

Kickix, Loc. cit. p. $16, \mathrm{n} \cdot 18$.

Michaud, Loc. cit. p. 44, n· 73.

Iilict, Loc. cit. p. 125, n· 30.

Bouillet, Loc. cit. p. 41, n*36.

H. radiata. Maton et Rackelt, Loc. cit. p. 199, n. 19.

Turton, Loc. cit. p. $53, \mathrm{n} \cdot 20$.

Habite les champs, les bois, les jardins, sous les pierres, sous les feuilles mortes, sous les haies et sur les vieux arbres; on ne peut plus commune, et cependant multiplie peu : je n'ai jamais vu leur ponte produire plus de vingt à trente œufs; ceux - ci sont globuleux. blancs et opacques; ils ont environ deux tiers de millimètre de diamètre, et éclosent, suivant l'époque où ils ont été déposés, du treizième au vingtième jour de leur ponte, qui a lieu depuis le mois de Mai jusqu'en Septembre; ils sont adultes vers la fin de lcur première aunée.

\section{N. 28. Hélice locide. Helix lucida.}

Draparnaud, Loc. çit. p. 103, n. 34, pl. 8, f. 11, 12.

Brard, Loc. cit. p. 34, pl. 2, f. 3, 4.

Des Noutins, Loc. cit. p. 4S, n-10. 
Blainville, Dict. sc. nat. t. 20, p. 432.

Grateloup, Ioc. cit. p. $109, \mathrm{n} \cdot 19$.

Kick $x$, Loc. cit. p. 22, n. 24.

Michaud, Loc. cit. p. 44, n* 75.

Millet, Loc. cit. p. $123, \mathrm{n} \cdot 20$.

Bouillct, Loc. cit. p. 41, n. 3\%.

H. nitida. Fírussac, Tabl. syst. p. 41, n-218.

- Lamarck, Loc. cit. p. 91, n'9\%.

- Payraudeau, Loc. cit. p. 101, n. 211.

- Collard-des Chorres, Loc. cit. p. 96, n. 9.

H. nitens. Maton et Rachett, Loc. cit. p. 198, n• 17.

Turlon, Loc. cit. p. 52, n· 18.

Habite les lieux marécageux, sur la vase des bords des ruisseaux et des rivières, dans le voisinage des sources de nos falaises; très-commune. Je ne connais pas ses œufs.

N. 29. Héltce hoisante, Helix nilida.

Draparnaud, Loc. cit. p. 117, n. 54, pl. S, f. 23.25.

Brard, Loc. cit. p. 31, pl. 2, f. 2.

Des Moutins, Loc. cit. p. 49, n. 30.

Blainville, Loc. cit. 1. 20, p. 433.

Gratcloup, Loc. cit. p. $110, \mathrm{n} \cdot 20$.

Michaud, Loc. cit. p. 44, n. 76.

Millet, Los. cit. p. $125, \mathrm{n} \cdot 31$.

Bouillet, Loc. cit. p. $42, \mathrm{n} \cdot 38$.

H. celiaria. Férussac, Tabl. syst. p. 41, n 212.

- Lamarck, Loc. cit.. p. 91, n. 96.

Payraudau, Loc. cit. p. 100, n. 210.

Collard-des-Cherres, Loc. cit. p. 97, n-16.

Kich $x$, Loc. cit. p. 15, n-16.

H. nitens. Maton et Rackitt, Loc. cit. p.198, n·17, pl. 5, f. 7.

- Twrton, Loc. cit. p. $52, \mathrm{n} \cdot 18$.

$\longrightarrow$ Grateloup, Loc. cit. p. 112, n. 22.

Habite les lieux très-humides, sous les pierres, et, dans les bois, sous les feuilles mortes et pourries; commune. Eile fait sa ponte de Mars en Sepiembre, et celle-ci sc compose de trente à cinquante œufs globulcux, blanchàtres, d'un millimètre et demi de diamètre; ces œufs 
éclosent au bout de quinze à seize jours, et les jeunes Hélices atteignent leur dernier degré d'accroissement dans les premiers mois de leur seconde année. J'ai toujours reçu des Anglais cette espèce, confondue avec la précédente, sous le nom d'Helix nitens.

N. 30. Hélice cristalline. Helix crystallina.

Draparnaud, Loc. cit. p. 118, n. 56, pl. 8, f. 1317.

Férussac, Tabl. syst. p. 41, n·223.

Des Moutins, Loc. cit. p. $50, \mathrm{n} \cdot 22$.

Blainville, Loc. cit. t. 20 , p. 432.

Graleloup, Loc. cit. p. $112, \mathrm{n} \cdot 23$.

Collard-des-Cherres, Loc. cit p. $98, \mathrm{n} \cdot 1 \%$.

Kick.x, Loc. cit. p. 12, n. 11.

Michaud, Loc. cit. p. $46, \mathrm{n} \cdot 79$.

Millet, Loc. cit. p. $126, \mathrm{n} \cdot 33$.

Bouillet, Loc. cit. p. $43, \mathrm{n} \cdot 41$.

Cette jolie pelite espèce, assez commune dans les herbes des lieux très-humides, et particulièrement sur les bords des rivières, est très-timide; son corps, long de cirq millimètres sur trois-quarts de millimètre de largeur, est de couleur gris-clair; ses tentacules supérieurs, d'un millimètre et demi de longueur, sont noir-d'ébène, colorés par le nerf rétracteur, qui forme aussi, de chaque côté du cou, une petite bande de même couleur; les tenfacules inférieurs ont à peine un demi-millimètre, et sont gris; le plan locomoteur est blanchâtre. Je ne connais point ses œufs.

\section{Genre Ambrette. Succinea. Draparnaud.}

N. 31. Ambrette AMphibie. Succinea amphibia.

Draparnaud, Loc. cit. p. 58. n* 1, pl. 3, f. 22, 23.

Lamarck, Loc. cit. p. 135, n. 2.

Brard, Loc. cit. p. 72, pl. 3, f. 1,2.

Des Moulins, Loc. cit. p. 55, n-1.

Gralcloup, Loc, cit. p. 121, n.1. 
Collaru-des-Cherres, Loc. cit. p. 102, n' 1.

Kick $x$, Loc. cit. p. 33, n· 3\%.

Michaud, Loc. cit. p. 48, n- 1.

Millet, Loc. cit. p. 126, n. 34 .

Bouillet, Loc. cit. p. 4'i, n. 42.

S. Putris, Blainville, Dict. sc. nat. t. 51, p. 244, pl. 38, f. 4.!

H. Pulris. Férussac, Tabl. syst. p. 26, n・9.

Hist. Noll. pl 11. f. 4,6,8,9,13 et pl. 11, A, f. 10 .

H. Succinea. Maton et Rachett, Loc. cit. 218, n-59.

Turton, Loc. cit.p. 6\%, n. $5 \%$.

Habite tous les lieux très-humides, sur les bords des sources, des ruisseaux, des mares, des rivières, etc.; trèscommune et très-variée dans la forme de sa coquille, qui est plus ou moins grande, ventrue, ou élancée, et dans sa couleur, qui est plus ou moins foncée. Elle fait sa ponte de Mai en Août, et ses œufs, au nombre de cinquante à soixante-dix, sont toujours agglomérés par une matière albumineuse légèrement succinée, qui les fixe à la base des plantes, sous les pierres, ou en terre, comme ceux des hélices. Ces œufs diffèrent de grosseur, suivant les variétés qui les ont pondus; ils ont depuis un millimètre jusqu'à un millimètre et demi de diamètre; ils sont globaleux, jaunâtres et hyalins; ils éclosent au bout de quatorze ou quinze jours, et les petits deviennent adultes vers la fin de leur première année. Ils hibernent de bonne heure et passent l'hiver fixés sous les pierres, au moyen de leur épiphragme, qui est vitreux.

\section{N. 32. Aybrette oblongue, Succinca oblonga.}

Draparnaud, Loc. cit. p. 59, n・2, pl. 3, f. 24, 25.

Lamarck, Loc. cit. p. 135, n* 3 .

Gratcloup, Loc. cit. p. 123, n・ 2.

Michaud, Loc. cit. p. 48, n- 2.

Millet, Loc cit. p. 126, n- 35.

Bouillet, Loc. cit. p. 45, n. 43.

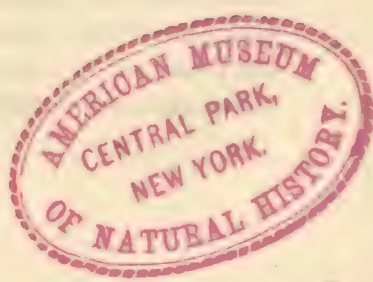




\section{4}

H. Etongata. Férussae, Tabl. syst. p. 2\%, n・ 10.

Hịst. Moll. pl. 11, f. $2,3$.

Habile les digues de la Liane et dans les herbes qui sont à la base des murs humides des villages de la côte. Ses œufs sont șeulement un peu plus petits que ceux de l'espèce qui précède; leur développement est absolument le même : moins commune que la $S$. amphibia.

IN. 33. AMbrette des SAbles. Succinea aremaria. Nob.

Animal entièrement noir.

Coquille ovale assez épaisse, translucide, striée longitudinalement, de couleur de corne foncée; trois à quatre tours de spire, dont le dernier égale les trois-quarts de la coquille. Ouverture assez grande, ovale-arrondie, et un peu oblique. Longueur des plus grands individus, sept à huit millimètres; largeur, cinq millimètres et demi. Habite les dunes de Camier, à cinq lieues sud de Boulogne. L'animal recouvre constamment sa coquille d'une humeur visqueuse; en hiver, il s'enfonce dans le sable, et forme un épiphragme vitreux assez solide.

Cette coquille diffère de celle de l' $A$. oblongue, figure première de la planche onze de l'Histoire des Mollusques de Férussac (1), avec laquelle elle a le plus de rapport pour la taille, en ce qu'elle est constamment plus épaisse, plus courte, plus ventrue, moins oblique, et que son ouverture est plus arrondie.

(1) Voici ce que m'écrivit cet estimable savant au sujet d'un envoi de coquilles terrestres de notre pays que je lui fis. "Entièrement absorbé par les Céphalopodes, c'est vous dire, Monsieur, que je n'ai pu accorder toute l'attention désirable à votre joli envoi de coquil!es : j'ai été frap pé cependant d votre Succinea arenaria et de votre petit Aspersa ; je n'avais jamass vu de varićté si petite. Cet envoi, au lotal, est curi eux et inferessant; on y voit l'influence de la localité marıtime, etc." 
Genre Buline. Bulimus. Brugnière.

N. 34. Bunime obscere. Bulimus obscurus.

Draparnuud, Loc, cit. p. 74, n· 3, pl. 4, f. 23.

Brard, Loe. eit. p. 97, pl. 3, f· 49.

Des Moutins, Loc. cit. p. 53, n- 1.

Grateloup, Loc. cit. p. 124, n・ 1 .

Kick $x$, Loc, cit. p. 37, n- 41.

Michaud, Loc. cit. p. 59, n. 4.

Millet, Loc. cit. p. 126, n' 36.

Bouillet, Loc. cit. p. 48, n. 45.

B. hordcaceus. Lamarck, Loc. cit. p. $125, n \cdot 33$.

Blainville, Dict sc. nat. t. 5 , supp. p. 128.

H. obscura. Férussac, Tabl. syst. p. 56, n· 424.

Maton et Racticlt, Loc. cit. p. 212, n.49, pl. 5, f. 11.

Turion, Loc. cit. p. $64, \mathrm{n} \cdot 50$.

Habite les fossés des fortificalions, sur les pierres, les vieux murs des habilations champêtres; les bois, sur les arbres : assez commun. Ses œufs, pondus de Mai en Septembre, sont peu nombreux, mais sont très-gros en proportion de l'animal; ils sont ovales-arrondis, blanchâtres ou opalins; ils ont un millimètre et demi de diamètre longitudinal, sur un millimètre un quart de diamétre transversal. La ponte de chaque individu dépasse rarement douze à quinze œufs, qui éclosent vers leur quinzième jour; les petits n'atteignent leur dernier degré d'accroissement que dans les premiers mois de leur seconde année. Ils hibernent de bonne heure, et forment un épiphragme vitreux, quelquefois blanchâtre.

N. 35. Bulme brillant. Bulimus lubricus.

Draparnaud, Loc. cit. p. 75, n. 4, pl.4, f. 24.

Lamarck, Loc. cit. p. 126 , n. 34.

Blainville, Dict. sc. nat. t. 5, supp. p. 128.

Brard, Loc. cit. p. 98, pl. 20, f. 3.

Des Moutins, Loc. cit. p. $53, \mathrm{n} \cdot 2$.

Collard-des-Cherres, Loc. cit. p. 101, n-2. 
Kickx, Loc. cit. p. 37, n. 42.

1. Uubrica. Michaud, Loc. cit. p. 51, n*1.

Millet, Loc. cit. p. 127, n' 38.

Bouillet, Loc. cit. p. 48, n. 46.

H. tubrica. Férussac, Tabl. syst. p. 51, n• 374.

Maton et Rackett, Loc. cit. p. 213, n· 5, pl. 5, f. 12.

Turton, Loc. cit. p. $64 ; \mathrm{n} \cdot 51$.

Habite sous les pierres et les feuilles mortes des lieux ombragés, sur les bords des sources et des ruisseaux; tr ès-commun. Je ne connais pas ses œufs.

N. 36. Bulime AIgU. Bulimus acritus.

Draparnaud, Loc. cit. p. \%7, n. 7, pl. 4, f. 29, 30.

Lamarck, Loc. cit. p. $125, \mathrm{n} \cdot 30$.

Payraudeau, Loc. cit.p 104, n·226.

Des Moulins, Loc. cit. p. $53, \mathrm{n} \cdot 3$.

Grateloup, Loc. cit.p. $126, \mathrm{n} \cdot 3$.

Collard-des-Cherres, Loc. cit. p.101, n+1.

Kicks, Loc. cit. p. $36, \mathrm{n} \cdot \mathbf{4 0}$.

Michaud, Loc. cit. p. $50, \mathbf{n} \cdot 6$.

Millet; Loc. cit. p. $126, \mathbf{n} \cdot 37$.

H. acuta. Férussao, Tabl. syst. p. $52, \mathrm{n} \cdot 378$.

H. bifasciata. Maton et Rackelt, Loc. cit. p. $210, \mathbf{n} \cdot 45$.

Turton, Loc. cit. p. $63, \mathrm{n} \cdot 46$.

Je n'ai point encore trouvé celte coquille avec son animal en vie : je l'ai jusqu'à présent recueillie dans les alluvions du Wimereux.

Genre Agathine. Achatina. Lamarck.

N. 37. Agathine aiguinete Achatina acicula.

Lamarck, Loc cit. p. $133, \mathrm{n} \cdot 19$.

Les Moulins, Loc. cit. p. $54, \mathrm{n} \cdot 1$.

Grateloup, Loc. cit. p.128, n. 1.

Collard-des-Cherres, Loc. cit. p. $101, \mathrm{n} \cdot 1$

Michaud, Loc. cit. p. $53, \mathrm{n} \cdot 3$.

Millet, Loc. cit. p. 12\%, n. 2.

Bouillet, Loc. eit. p. 49, n. 47. 
B. aciculu. Draparnaud, Loc. cit. p. 75, n $3, p] .4$, f. $25,26$. Blainville, Loc. cit. t. 5 , supp. p. 129.

Brard, Loc. cit. p. 100 , pl. 3, f. 21.

Kickx, Loc. cit. p. $38, \mathrm{n} \cdot 43$.

1I. acicula. Férussac, Tabl. syst. p. 51 , n- 371.

Buccinuan terrestre. Maton et Racketl, Loc. cit. p. 139 , n-13. Turton, Loc. cit. p. 18 , n. 15.

Habite sur les bords des ruisseaux et des rivières, sous les pierres et les détritus de plantes; très-commun. Je ne connais pas ses œufs.

Genre Chausilie. Clausilia. Draparnaid.

N.3S. Clausilie lisse. Clausilia bidens.

Draparnaud, Loc. cit. p. 68 , n* 1, pl. 4, f. 5.7.

Brard, Loc. cit. p. 83 , pl. 3 , f. 9.

Blainville, Dict. sc. nat. 1. 9, p. 364.

Des Moulins, Loc. cit. p. 52, n-1.

Collard-des-Cherres, Loc. cit. p. 101, n· 3.

Kick $x$, Loc. cit. p. $40, n \cdot 45$.

Michaud, Loc. cit. p. 54, n. 1.

Millet, Loc. cit. p. 127, n・ 40.

Bouillet, Loc. cit. p. $50, \mathrm{n} \cdot 4 \mathrm{~S}$.

H. derugata. Férussac, Tabl. syst. p. 63, n- 529.

Turbo laminatus. Maton et Racketl, Loc. cit. p. 179, n. 47.

Tarton, Loc. cit. p. 224, n. S0.

Habite nos chantiers, sur les pièces de bois, et sous les haies du Vallon de Beaurepaire; assez commune. Les animaux de ce genre varient, dans la même espèce, du gris au noir le plus foncé; ils sont tous fortement chagrinés par de gros points noirs, ovales, dont les interstices sont beaucoup plus clairs. Ils multiplient fort peu; mais leurs œufs sont énormes, vu la petitesse des animaux: ces $œ u f s$, qui sont plus gros que l'ouverture de la coquille n'est large, ont environ deux millimètres de diamètre; ils sont un peu ovoïdes et blanchâtres, et leur nombre dépasse rarement dix à douze; ils éclosent vers le vingtième jour 
fle leur ponte, et les jeunes individus ne sont adultes que vers la fin de leur seconde année. Epoque de la ponte, Août, Septembre.

Cette Clausilie, ainsi que les suivantes, ont toutes un osselet operculaire (Clausilium, Draparnaud), spathuliforme; sa partic supérieure, c'est-à -dire celle qui ferme hermétiquement la coquille derrière le second plis de la columelle, est ovalaire, libre, très-blanche et brillante, cintrée longiludinalement, concave en dehors, convexe en dedans, et bordée d'un bourrelet blanc beaucoup plus épais sur le bord extérieur, au sommet duquel il forme, chez les vieux individus, un petit tubercule. Cette partie ovalaire, ou operculaire, est aussi ornée de trois ou quatre stries longitudinales d'accroissement; elle se rétrécit subitement à sa base, et se continue en une petite lame du quart de sa largeur, mais aussi longue qu'elle, qui descend entre les deux plis décurrents de la columelle, et se fixe un peu en arric̀re de leur naissance, à-peu-près où commence l'arant-dernier tour de spire. Pendant la vie de l'animal, celte petile lame est membraneuse; mais à sa mort elle devient dure et cassante, comme sa partie supérieure. L'osselet de la Clausilie lisse a une échancrure qui prend le tiers supérieur du bord extérieur de la partie operculaire; toutes les autres espèces ont celle partie entière.

N. 39. Cladjille silide. Clausilia solida.

Draparnaud, Loc. cit. p. $69, \mathrm{n} \cdot 2$, pl.4, f. 8, 9.

Blainvilte, Loc. cit. t. 9 , p. 364.

Michaud, Loc. cit. p. 54, n' 2.

H. solida. Férussac, Loc. cit. p. 63, n. 535.

Turbo labialus. Maton et Rackett, Loc. cit. p. $180, \mathrm{n} \cdot 50$.

Turton, Loc. cit. p. 225, n· 83.

Commune dans les alluvions de Wimereux. 
N. 40. Crausrite ventrue. Clausilia ventricosa.

Draparnaud, Loc. cit. p. 71, n.6, pl. 4, f. 14.

Blainville, Loc. cit. t. 9 , p. 365.

Michaud, Loc. cit. p. $56, \mathrm{n} \cdot 7$.

Bouillet, Loc. cit. p. $51, \mathrm{n} \cdot 50$.

H. ventricosa. Férussac, Tabl. syst. p. 63, n. 531 .

Turbo biplicatus. Malon et Rackett, Loc. cit. p. $179, \mathrm{n} \cdot 48$. Turlon, Loc. cit. p. $224, n \cdot 81$.

Habite sous les haies des lieux humides, et sur les vieux arbres dans les bois.

N. 41. Clausilie rugeuse. Clausilia rugosa.

Draparnaud, Loc. cit. p. 73, n· 9, pl. 4, fig. 19, 20.

Lamarck, Loc. cit. p. 115, n- 12.

Brard, Loc. cit. p. 85, pl. 3, f. 10.

Blainville, Dict. sc. nat. t. 9 , p. 365 .

Payraudear, Loc. cit. p. 104, n. 224.

Des Moulins, Loc. cit. p. 52, n' 3 .

Graleloup, Loc. cit. p: 130, n: 1 .

Collara-des-Cherres, Loc, cit. p. 101, n- 2.

Kick $x$, Loc. cit. p. $39, \mathrm{n} \cdot 44$.

Michaud, Loc. cit. p. 57, n. 10.

Millet, Loc. cit. p. 127, n- 42.

Bouillet, Loc. cit. p. $52, \mathrm{n} \cdot 51$,

II. rugosa. Firussac, Tabl. syst: p. 63, n. 543.

Turbo nigricans. Maton et Ruckelt, Loc. cit. p. $180, \mathrm{n} \cdot 49$. Turlon, Loc. cit. p. 225, n. 82.

Habite les fossés des fortifications, et sous les pierres des lieux humides; commune. Ses œufs sont déposés en Août et Septembre; ils ont un millimètre et demi de diamétre, et sont, du reste, semblables à ceux de la Clausilie lisse.

N. 42. Clausinie Plicatole. Clausilia plicalula.

Draparnaud, Loc. cit. p* 72, n.8, pl. 4, f. 1\%, 18.

Lamarck, Loc. cit: p. $115, \mathrm{n} \cdot 11$.

Blainville, Loc. cit: p. $365, \mathrm{t} .9$.

'nyraudeau, Loc. cit. p. 103 , n: 228.

Des Mloutins, Loc. cit. p. 52, n: . 
Grateloup, Loc. cit. p. $132, \mathrm{n}^{\cdot} 3$.

Kicho, Loc. cit. p. $43, \mathrm{n} \cdot 49$.

Miohaud, Loc. cit. p. 5\%, n. 9.

H. plicalula. Férussac, Tabl. syst. p. 63, n. 540 .

Habite sur les vieux arbres et les vieux murs; trèscommune. Ses œufs, de la même grosseur que ceux de l'espèce qui précède, sont aussi pondus à la même époque; leur éclosion a lieu au bout de dix-huit à vingt jours, et les jeunes individus n'atteignent leur dernier degré d'accroissement que vers la fin de leur seconde année.

N. 43. Cladsilie parvex. Clausitia parvula.

Michaua, Loc. cit. p. 57, n.11, pl. 15, f. 21-25.

Des Moulins, Loc. cit. p. $53, \mathrm{n} \cdot 4$.

Grateloup, Loc. cit. p. 131, n. 2.

Millet, Loc. cit. p. 128, n: 43.

Bouitlet, Loc. cit. p. $52, \mathrm{n} \cdot 52$.

C. rugosa, v. e. Draparnaud, Loc. cit. p. 73, n-9.

C. minima. Kick $x$, Loc. cit. p. $41, \mathrm{n} \cdot 47$.

H. parvula. Férussac, Tabl. syst. p. 63 , n. 544.

Habite les vieux murs, dans la mousse, et sur les vieux arbres; commune.

\section{Genre Marlzot. Pupa. Draparnaud.}

N. 44. Marlot tridental. Pupa tridentalis.

Michaud, Loc. cit. p. $61, \mathrm{n} \cdot 2$, pl. 15, f. 28, 29, 30.

Dans les alluvions du Wimereux; assez commun.

N. 45. Mamlot вовdÉ. Pupa marginata.

Draparnaud, Loc. cit. p. 61, n. 6, pl. 3 , f. 36-38.

Brard, Loc. cit. p. 93 , pl. 3 , f. 15-16.

Blainville, Dict. sc. nat. t. 28 , p. 95.

Grateloup, Loc. cit. p. 134, n: 2 .

Des Moulins, Loc. cit. p. $51, \mathrm{n} \cdot 3$. 
Collard-des-Cherres, Loc. cit. p. 100, n*4.

Michaud, Loc. cit. p. $62, \mathrm{n} \cdot 3$.

Millet, Loc. cit. p. 128, n. 44.

Bouillet, Loc. cit. p. $53, \mathrm{n}: 53$.

P. muscorum. Lamarck, Loc. cit. p. 111, n. 27.

H. muscorum. Férussac, Loc. cit. p. 59, n. 475.

Turbo muscorum. Maton et Rackett, Loc. cit. p. $182, \mathrm{n} \cdot 54$. Turton, Loc. cit. p. $220, n \cdot 69$.

Habite sous les haies, les feuilles mortes, et dans les fissures des écorces des arbres; très-commun.

N. 46. Marllot ombiriqué. Pupa umbilicata.

Draparnaud, Loc. cit. p. 62, n. 7. pl. 3, f. 39-40.

Lamarck, Loc. cit. p. 111, n-26.

Blainville, Dict. sc. nat. t. 28, p. 95.

Des Moutins, Loc. cit. p. 51, n-4.

Grateloup, Loc. cit. p. 133, n' 1.

Collard-des-Cherres, Loc. cit. p. 99, n. 3.

Kick $x$, Loc. cit. p. $46, \mathrm{n} \cdot 54$.

Michaud, T.oc. cit. p. $62, \mathrm{n} \cdot 4$.

Millet, Loc. cit. p. 128, n. 45.

H. umbilicata. Férussac, Loc. cit. p. 59 , n. $4 \% 4$.

Turbo muscorum. Maton et Rackett, Loc. cit. p. 182, n. 54 .

Turton, Loc. cit. p. $220, \mathrm{n} \cdot 69$.

Habite sous les pierres et les détritus de plantes de nos dunes et de nos falaises; très - commun.

N. 47. Maillot seigle. Pupa secale.

Draparnaud, Loc. cit. p. 64 , n. 13 , pl. 3, f. 49, 50.

Lamarck, Loc. cit. p. $110, \mathrm{n} \cdot 21$.

Des Moulins, Loc. cit. p. $52, \mathrm{n} \cdot 8$.

Blainville, Loc. cit. t. 28 , p. 98 .

Kick $x$, Loc. cit. p. $46, \mathrm{n} \cdot 53$.

Michaud, Loc. cit. p. 64 , n* 11.

H. secale. Férussac, Tabl. syst. p. 60, n· 488.

Trouvé dans les alluvions du Wimereux; assez com mun. 
N- BS. Maillot roment. Pupa fromentum.

Draparnaud, Loc. cit. p. 55, n. 14, pl. 3, f. $51,52$.

Lamarck, Loc. cit. p. 109, n. 20.

Blainville, Dict. sc. nat. t. 28, p. 98.

Michaed, I.oc. cit. p. $65, \mathrm{n} \cdot 13$.

H. frumentum. Férussac, Tabl. syst. p. 60, n. $48 \%$.

Trouvé dans les alluvions du Wimereux; assez rare.

N. 49. Maillot fragilf. Pupa fragilis.

Draparnaul, Loc. cit. p. 68 ; n. 20 , pl. 4 , f. 4 .

Lamarck, Loc. cit. p. 110, n. 24.

Blainville, Loc. cit. t. 28, p. 94.

Collard-des-Cherres, Loc. cit. p. 99 , n. 2.

Kickw, Loc. cit. p. 44, n. 50.

Michaud, Loc. cit. p. $67, \mathrm{n} \cdot 20$.

Millet, Loc. cit. p. $128, \mathrm{n} \cdot 46$.

Bouillet, Loc. cit. p. 55, n. 5\%.

H. perversa. Férussac, Tabl. syst. p. 62, n- 511.

Turbo perversus. Maton et Rackett, Loc. cit. p. $171, \mathrm{n} \cdot 51$, pl. 5, f. 2.

Turton, Loc. cit. p. 226, n. 84 .

Habile nos dunes, sur les plantes herbacées, dans les champs, sur les arbres et sur les vieux murs; trés-commun. Sa ponte se compose de douze à quinze œufs aussi très-gros; ils sont blanchâtres et globuleux, et ont un millimètre un quart de diamètre. Ces œufs, déposés au commencement de l'aulomne, éclosent vers le quinzième ou vingtième jour de leur ponte, et les petits deviennent parfaits à la fin de leur première année.

\section{Genre Vertigo. Vertigo. Muller.}

N. 50. Vertigo anti-vertigo. Verligo antivertigo.

Draparnaud, Loc. cit. p. 60, n-4, pl. 3, f. 32, 33.

Blainville, Dict. sc. nat. t. 28, p. 97.

Collard des-Cherres, Loc. cit. p. $100, n \cdot \%$.

Kickx, Loc. cit. p. $50, n \cdot 61$. 
Michaud, Loc. cit. p. 72, n* 4.

Vertigo septemdentata. Ferussac, Tabl, syst. p. 64, n· 7 .

Turbo sexdentatus. Maton et Rackett, Loc. cit. p. 183, n- 55. Turton, Loc. cit. p. $221, \mathrm{n} \cdot 71$.

Habite nos falaises, sous les pierres des lieux humides; l'animal est entièrement noir : assez commun.

Genre Cary chie. Carychium. Muller.

N. 51. Carterie myosote. Carychium myosote.

Michaud, Loc. cit. p. 73, n॰1.

Auricula myosolis. Draparnaud, Loc. cit. p. $56, \mathrm{n} \cdot 1$ 1, pl. 3 , fig. 16,17 .

Férussao, Tabl. syst. p. 103, n. 8 .

Lamarck, Loc. cit. p. 140, n• 9.

Payraudear , Loc. cit. p. 104, n'228.

Voluta denticulata. Maton et Rackett, Loc. cit. p. 130, 11.2.

Turlon, Loc. cit. p. $249, \mathrm{n} \cdot 2$.

Habile les digues de la Liane, dans les pierres siluées au-dessus du niveau ordinaire de ses eaux; assez commune. Son animal diffère, seulement par la couleur, de celui de l'espèce suivante, dont la nourriture, l'accouplement, les œufs et le développement des petils sont absolument les mêmes.

N. 52. Carychie pensonnée. Carychium personnalum.

Michaud, Loc. cit. p. 73, n• 2, pl. 15, n· $42,43$.

Animal assez épais, d'un blanc jaunâtre, quelquefois légèrement violacé à la partie supérieure de son corps, qui est finement ridé; lête proboscidiforme, portant deux tentacules cylindriques un peu renflésà leur sommet, assez gros et courts, longs d'un millimètre et demi, annelés de blanc et de griș bleuâtre; ils sont oculés un peu en arrière de leur base interne. Mufle, tête et cou ridés transversalement, légèrement chagriné sur les côtés. On voil ches 
les individus adultes, deux taches rondes, rousses, situées à la partie de la tête où sont ordinairement les tentacules inférieurs. Organes génitaux au côté droit; celui du mâle a la base du tentacule et l'organe femelle à l'entrée de la cavité respiratrice. Nanteau jaunâtre, uni à sa circonférence; plan locomoteur blanchâtre, arrondi à sa partie antérieure, et terminé en pointe mousse. Longueur, huit millimètres; largeur, deux millimètres et demi. Lorsque cet animal rampe sur une plaque de verre, on ne voit qu'une seule ondulation à la fois, produite par les fibres musculaires du pied; cette ondulation part de l'extrémité postérieure du pied, et se termine à son extrémité antéricure avant qu'un autre commence. Cet animal est peu craintif; lorsqu'on le prend par sa coquille, il s'allonge et cherche à trouver un point d'appui; il est tròscommun sous les pierres des digues du port de Wimereux, mais seulement sous celles situées au-dessus du niveau de la pleine mer. Il se nourrit de détritus de plantes marines et de bois pourri. Il aime les lieux humides, obscurs et saumâtres. Je ne l'ai point trouvé sous les pierres baigrées journellement par l'eau de la mer; cependant il peut virre assez long-temps dans l'eau salée, tandis qu'il menrt peu de temps après son immersion dans l'eau douce. Il pond, dans les mois de Juin à Septembre, douze à trente œufs, réunis par une matière visqueuse qui en forme un petit greupe, qu'elle fixe sous les pierres les phus humides. Ces œufs sont globuleux, jaunâtres et entièrement diaphanes; ils ont environ deux tiers de millimètre de diamètrc. Leur éclosion a lieu vers le quinzième jour de leur ponte, et ils ne sont adultes qu'à la fin de leur seconde année. Ils n'hibernent point.

Coquille ovale, alongée, assez épaisse, translucide et quelçncfois opaque, de conleur faure ou jaunâtre, et 
ayant toujours les premiers tours de spire brunâtres; lisse, luisantc. Spire composée de huit tours peu convexe, dont le dernier égale les deux tiers de la coquille. Sommet. aigü, sulure assez prononcée. Ouverture oblongue, souvent très-inclinée en arrière; columelle garnie quelquefois de quatre plis, mais le plus ordinairement de trois, le supérieur manquant souvent; péristome jaunâtre, garni intérieurement d'un bourrelet blanc assez épais, portant de une à sept dents. J'ai souvent observé des individus ayant le bord latéral orné, près de l'ouverture, de deux et trois de ces bourrelets, garnis de cinq à sept dents chacun; et d'autres dont la coquille est ordinairement très-mince, avoir ces dents remplacées par des plis décurrents sur le bord latéral, qui forment sur chaque tour de spire, à l'extérieur, autant de petites bandes blanchâtres et opaques : cette dernière variété est toujours plus petite et plus étroite que l'espèce typique, dont elle a le même nombre de tours de spire. Longueur de l'espèce principale, dix millimètres; largeur, quatre millimètres et demi. Cette description diffère, comme on le voit, de celle de la même espèce donnée par M. Michaud; les différences qui existent entre elles me font penser que cet estimable naluraliste n'arait à sa disposition, à l'époque ou il l'a faite, que des individus non entièrement adultes et décolorés.

N. 53. Carychie pygmée. Carychium minimum.

Férussac, Tabl. syst. p. $100, \mathrm{n} \cdot 2$.

Michaud, Loc. cit. p. $74, \mathrm{n} \cdot 3$.

Grateloup, Loc. cit. p. 138, n·1.

Kiclix, Loc. eit. p. 51, n•62.

Millet, Loc. cit. p. $129, \mathrm{n} \cdot 49$.

Bouillet, Loc. eit. p. 5S, n. 62 .

Auricula minima. Draparnaud, Loc. cit. p. 5\%, n. 3, pl. 3, fig. $18,19$. 
Auricula minima. Lamarck, Loc. cit. p. $140, \mathrm{n} \cdot 10$. Des Moulins, Loc. cit. p. 55, n-1.

Collard-des-Cherres, Loc. cit. p. 102, n-1.

Turbo carychium. Maton et Rackett, Loc. cit. p. 194, n. 57. Turton, Loc. cit. p. 221, n. 72 .

Animal blanchâtre, opaque, portant deux tentacules gris, courts et obtus; plan locomoteur arrondi postérieurement. Longueur, un millimètre et demi ; largeur, un demi - millimètre.

Habite les bords des ruisseaux, sur les détritus de plantes, sous les haies, sur les feuilles mortes et pourries, et sous les pierres des lieux humides de nos falaises; trèscommune.

Genre Crclustome. Cyclostoma. Lamarck.

N. 54. Crclostome ÉlÉgant. Cyclostoma elegans.

Draparnaud, Loc. cit. p. 32, n.1, pl. 1, f. 5-8.

Lamarck, I.oc. cit. p. 148, n· 26.

Brard, Loc. cit. p. 103 , pl. 3 , f. 7, 8 .

Payraudeau, Loc. cit. p. $105, \mathrm{n} \cdot 230$.

Des Moulins, Loc. cit. p. $55, \mathbf{n} \cdot 1$.

Blainville, Loc. cit. t. 12 , p. 298.

Grateloup, I.oc. cit. p. $139, \mathrm{n} \cdot 1$.

Collard-des-Cherres, Loc. cit. p. 103, n- 1.

Kick $x$, Loc. cit. p. $69, \mathrm{n} \cdot 87$.

Michaud, Loc. cit. p. $75, \mathbf{n} \cdot 1$.

Millet, Loc. cit. p. $129, \mathrm{n} \cdot 50$.

Bouillet, Loc. cit. p. 59, n· 63.

Turbo elegans, Maton et Rackelt, Loc. cit. p. 16\%, n. 25.

Turton, Loc. cit. p. $206, \mathrm{n} \cdot 33$, f. $48,49$.

\section{VARIÉTÉS.}

1. Cinerea autrufa, immaculata. Drap. a.

2. Cinerea, fusco maculata. Drap. b.

3. Cinerea, fasciis duabus fuscis, interruptis. Drap. g.

IIabite parmi les feuilles mortes des haies et des bois du haut Boulonnais et de l'Artois; commun. 


\section{7}

N. 55. Crchostome porntrlé. Cyclostoma maculalum.

Draparnaud, Loc. cit. p. 39 , n- 13 , pl. 1, f. 12.

Des Moulins, Loc. cit. p. 56, n・2.

Collard-des-Cherres, J.oc. cit. p. $103, \mathbf{n} \cdot 2$.

Michaud, Loc. cit. p. $76, \mathrm{n} \cdot 5$.

Habite nos bois, aux pieds des arbres, dans la mousse.

\section{TRACHÉLIPODES AQUATIQUES.}

\section{Genre Planonbe. Planorbis. Bruguière.}

N. 56. Planorbe entortmlé. Planorbis contortus.

Draparnaud, Loc. cit. p. 42 , n·1, pl. 1, f. 39-41.

Lamarck, Loc. cit. p. $154, \mathrm{n} \cdot 9$.

Brard, Ioc. cit. p. 157, pl. 6, f. 12-14:

Blainville, Dict. sc. nat. t. 41 . p. 227.

Grateloup, Loc. cit. p. 147, n. 4.

Collard-des-Cherres, Loc. cit. p. 103, n. 4.

Kicks, Loc. cit. p. $63, \mathrm{n} \cdot 78$.

Michaud, Loc. cit. p. $79, \mathrm{n} \cdot 1$.

Millet, Loc. cit. p. $130, \mathrm{n} \cdot 51$.

Bouillet, Loc. cit. p. $60, \mathrm{n} \cdot 64$.

Helix contorta. Maton et Rackett, Loc. cit. p. 191, n. \%.

Turton, Loc. cit. p. $48, n \cdot 9$.

Habite les fossés des fortifications et ceux de nos prairies; très-commun. Ses capsules, au nombre de six à huit, ont environ trois millimètres de diamètre, et contiennent chacune six à huit œufs d'un demi-millimètre de diamètre, dont l'éclosion à lieu au bout de dix à douze jours.

N. 5\%. PianoRbe CONNÉ. Planorbis corncus.

Draparnaud, Loc. cit. p. 43, n· 2, pl. 1, f. 42-44.

Lamarck, Loc. cit. p. $152, \mathrm{n} \cdot \mathbf{2}$.

Brard, Loc. cit. p. 14\%, pl. 6, f. 1, 2. 
Blainville, Dict. sc. nat. t. 41, p. 226.

Des Moutins, Loc. cit. p. 56, n: 2.

Collard-des-Cherres, Loc. cit. p.103, n·1.

Kickx, Loc. cit. p. $62, \mathrm{n} \cdot 76$.

Michaud, Loc. cit. p. $79, \mathbf{n} \cdot 2$.

Millet, Loc. cit. p. $130, \mathrm{n} \cdot 52$.

Bouillet, Loc. cit. p. $60, \mathrm{n} \cdot 65$.

Helix cornea. Maton et Rackett, Loc. cit. p. $190, \mathrm{n} \cdot 5$.

Turton, Loc. cit. p. 47, n· 6, f. 52.

Habite les fossés et les autres eaux stagnantes de l'Artois. Ce planorbe ne dépose qu'une ou deux capsules ovigères; mais celles-ci sont très-fortes, comparativement à celles des autres espèces de ce genre; elles contiennent aussi beaucoup plus d'œufs : j’en ai compté de vingt à quarante dans chaque. Les œufs sont globuleux ou un peu ovoïdes, et ont environ un millimètre un quart de diamètre; ils sont hyalins, et éclosent vers le seizième jour de leur ponte.

N. 5S. Planoree hispide. Planorbis hispidus.

Draparnaud, Loc. cit. p. $43, \mathrm{n} \cdot 3$, pl. 1, f. $453-48$.

Lamark, Loc. cit. p. $154, \mathrm{n} \cdot 10$.

Brard, Loc. cit. p. 159, pl. 6, f. 6, 7.

Blainville, Dict. sc. nat. t. 41 , p. 227.

Les Moulins, Loc. cit. p. $56, \mathrm{n} \cdot 3$.

Grateloup, Loc. cit. p. $150, \mathrm{n} \cdot 7$.

Kiok $x$, Loc. cit. p. 64, 79.

Michaud, Loc. cit. p. $79, \mathrm{n} \cdot 3$.

Millet, Loc. cit. p. 130, n' 53.

Bouillet, Loc. cit. p. 63 , n: 70 .

Hetix alba. Maton et Rackett, Loc. cit. p. $192, \mathrm{n} \cdot 8$. Turton, Loc. cit. p. $48, \mathrm{n} \cdot 10$.

Habitc la plus grande partie des mares, fossés et rivières de notre département; très-commun. Pond six à huit capsules de trois à quatre millimètres de diamètre, qui conliennent chacune quatre à dix œufs de trois-cinquièmes 
de millimètre de diamètre, qui éclosent au bout d'environ douze jours de leur ponte.

N. 59. Planoree tullé. Planorbis imbricatus.

Draparnaud, Loc. cit. p. 44, n. 4, pl. 1, f.49-5̆l.

Lamarck, Loc. cit. p. $155, \mathrm{n} \cdot 12$.

Brard, Loc. cit. p. 163 , pl. 6, f. $10,11$.

Blainville, Dict. sc. nat. t. 41, p. 228.

Des Moulins, Loc. cit. p. $5 \%, \mathrm{n} \cdot 4$.

Grateloup, Loc. cit. p. $151, \mathrm{n} \cdot \mathrm{S}$.

Kick $x$, Loc, cit. p. $67, \mathrm{n} \cdot 85$.

Michaud, Loc. cit. p. $80, \mathrm{n} \cdot 4$.

Millet, Loc. cit. p. $130, \mathrm{n} \cdot 54$.

Bouillet, Loc. cit. p. $61, \mathrm{n} \cdot 67$.

Turbo nautileus. Maton et Rackett, Loc. cit. p. 169, n·2\%, pl. 5 , fig. 4.

Turton, Loc. cit. p. 227, n· 88, f. 78, mala.

Habite les fossés des forlifications; ses capsules ont à peine un millimètre et demi de diamètro ; elles contiennent trois à six œufs d'environ un quart de millimètre de diamètre, dont l'éclosion a lieu au bout de dix à douze jours.

N-60. Pranorbe dentelé. Planortis ctistatus.

Draparnaud, Loc. cit. p. 44, n· 5, pl. 2, f. 1-3.

Des Moulins, loc. cit. p. $57, \mathrm{n} \cdot 5$.

Blainville, Dict. sc. nat. t. 41, p. $22 \mathrm{~S}$.

Grateloup, Loc. cit. p. $152, \mathrm{n} \cdot 9$.

Kickx, Loc. cit. p. $68, \mathrm{n} \cdot \mathrm{S6}$.

Michaud, Loc. cit. p. $80, \mathrm{n} \cdot 5$.

Millet, Loc. cit. p. $130, n \cdot 55$.

Bouillet, Loc. cit. p. 61, n. 66 .

Habite les petites mares et les fossés des dunes do Wimereux; assez commun.

N. 61. Planorbe contourní. Planorbis vorlex.

Draparnaud, Loc. cit. p. $44, \mathrm{n} \cdot 6$, p]. 2, f. $4-7$.

Lamarck, Loc. cit. p. $154, \mathrm{n} \cdot 7$. 
Brard, Loc. cit. p. 154, pl. 6, f. 8-9.

Blainville, Dict. sc. nat. t. 41, p. 22\%.

Des Moulins, Loc. cit. p. $5 \%, \mathbf{n} \cdot 6$.

Grateloup, Loc. cit. p. 148, n- 5 .

Collard-des-Cherres, Loc. cit. p. 103, n- 3.

Kick $x$, Loc. cit. p. $65, \mathrm{n} \cdot 82$.

Michaud, Loc. cit. p. $80, \mathbf{n} \cdot 6$.

Millet, Loc. cit. p. $131, \mathrm{n} \cdot \mathbf{5 5}$.

Bouillet, Loc. cit. p. $62, \mathrm{n} \cdot 68$.

Hetix vortex. Maton et Rackett, Loc. cit. p. $189, \mathrm{n} \cdot 4$.

Turton, Loc. cit. p. $46, \mathrm{n} \cdot 5$.

Habite presque tous les licux aquatiques du département; très-commun. Ses capsules ovigères ont environ quatre millimètres de diamètre, et contiennent jusqu’à douze œufs d'un demi-millimètre de diamètre, qui éclosent dix à douze jours après leur ponte.

N. 62. Planorbe leucostome. Planorbis leucostoma.

Millıt, Loc. cit. p. 131, n· 56.

Dos Mouline, Loc. cit. p. $58, \mathbf{n} \cdot 8$.

Graleloup, Loc. cit. p. $152, \mathrm{n} \cdot 10$.

Michaud, Loc. cit. p. 80, n. 7, pl. 16, f. 3-5.

Habite les fossés de nos grandes roules; Irès-commun.

N. 63. Plaxorbe comprimé. Planorbis compressus.

Michaud, Loc. cit. p. S1, n. S, pl. 16, f. 6-8.

P. vertex, var. A. Draparnaud, Loc. cit. p. $45, \mathrm{n} \cdot 6$.

Habite les fossés d'Aire à Moulin-le-Comte; commun. Ces deux dernières espèces diffèrent seulement du $P$. vortex, en ce que la première est moins carénée, et que la seconde l'est un peu plus; du reste, ce sont absolument les mêmes animaux, et leur ponte est aussi absolument la même. Ces légères différences suffisent-elles pour en faire des espèces? Je ne le pense pas. 
N. 64. Tlanone marginí. Planorbis marginatus.

Draparnaud, Loc. cit. p. 45, n• 8, pl. 2, f. 11,12 et 15.

Brard, Loc. cit. p. 152 , pl. 6 , f. 5.

Bluinuille, Loc. cit. t. 41, p. 228.

Des Moulins, Loc. cit. p. 58, n*9.

Graleloup, Loc. cit. p. 146, n' 2.

Kick $x$, Loc. cit. p. $64, \mathrm{n} \cdot 80$.

Michaud, Loc. cit. p. 82, n. 10.

Millet, Loc. cit. p. $131, \mathrm{n} \cdot 59$.

Bouillet, Loc. cit. p. $63, \mathrm{n} \cdot 71$.

Helix planorbis. Maton et Rackelt, Loc. cit. p. 188, n. 3, pl. 5 , fig. 13.

Helix complanata. Turton, Loc. cit. p. $46, \mathrm{n} \cdot \mathbf{4}$.

Habite la Slack, les marais de Condette et de Camier, les fossés de l'Artois et du Calaisis; très-commun. Ses capsules ovigères, au nombre de huit à dix, n'ont pas plus de trois millimètres de diamètre, et contiennent rarement plus de six œufs ovales-arrondis, d'environ troisquarts de millimètre de diamètre. Ce planorbe devient très-grand dans les marais de Conclette et Camier; il atteint souvent vingt millimètres de diamètre. Lorsque les fossés et les mares dans lesquels ils vivent viennent ì se dessécher, ces mollusques restent sur la vase, et ferment leur coquille arec un épiphragme vitreux; plusieurs fois j'en ai rapporté chez moi, où je les conservais encore vingt et trente jours hors de l'eau; les remettant ensuite dans ce liquide, je les trouvais en mouvement quinze à vingt minutes après leur immersion.

N- 65. Planobe Caréné. Planorbis carinalus.

Draparnaud, Loc. cit. p. $46, \mathrm{n} \cdot 9$, pl. 2, f. $13,14,16$.

Lamarck, Loc. cit. p. $153, \mathrm{n} \cdot 3$.

Brard, Loc. cit. p. 150, pl. 6 , f. 3.

Blainville, Loc. cit. t. 41, p. 226.

Grateloup, Loc. cit. p. 145, n' 1.

Kick $x$, Loc. cit. p. $65, \mathrm{n} \cdot 81$.

Michaud, Loc. cit. p. 82 , ค. 11. 
Millet, Loc cit. p: 131, n'60.

Bouillet, Loc. cit. p. 64, n* 72 .

IIelix planata. Malon et Rackent, Loc. cit. p. $189, \mathrm{n} \cdot 3^{*}$, pl. 5, f. 14.

Helix planorbis. Turlon, Loc. cit. p. $45, \mathrm{n} * 3$.

Habite les mêmes localités que l'espèce précédente; ses capsules et ses œufs sont de la même grandeur.

N. 66. Planorbe luisant, Planorbis nilidus.

Draparnaud, Loc. cit. p. 46, n. 10 , pl. 2, f. 17-19.

Blainville, Dict. sc. nat. t. 41, p. 228.

Michaud, Loc. cit. p. 82, n· 12.

Millet, Loc. cit. p. $131, \mathrm{n} \cdot 61$.

Bouillet, Loc. cit. p. $65, \mathrm{n} \cdot 72$.

P. clausulatus. Des Moulins, Loc. cit. p. $59, \mathrm{n} \cdot 10$.

Graleloup, Loc. cit. p. $153, \mathrm{n} \cdot 11$.

P. nautileus. Kickx, Loc. cit. p. $66, \mathrm{n} \cdot 83$.

Nautilus lacustris. Maton et Rackett, Loc. cit. p. 114, n· 1. Turton, Loc. cit. p. 117, n· 2.

Habite, avec l'espèce suivante, les fossés des fortifications et les fosses aux tourbes des marais de Condctte; leurs capsu'es ovigères ont environ un millimètre et demi de diamètre, et contiennent ordinairement quatre à huit œufs d'un tiers de millimètre de diamètre, qui éclosent dix ou douze jours après leur ponte.

N. 6\%. Planorbe apdatr. Planorbis complanatus.

Draparnaud, Loc. cit. p. 47, n* 11, pl.2, f. 20-22.

Brard, Loc. cit. p. 161, pl. 6, f, 4.

Gratcloup, Loc. cit. p. 147, n· 3.

Michaud, Loc. cit. p. 82, n.13.

Millet, Loc. cit. p. $132, \mathrm{n} \cdot 62$.

Bouillet, Loc. cit. p.64, n 73.

P. nilidus. Lamarck, Loc. cit. p. $155, \mathrm{n}: 11$.

Des Moulins, Loc. cit, p. $59, \mathbf{n} \cdot 11$.

- Blainville, Loc. cit. p. 41, n·22\%.

Collard-des-Cherres, Loc cit. p. $104, n^{\circ} 5$.

P. tenticularis. Kick $x$, Ioc. cit. p. 67, n. 84 .

Habile avec le précédent. 
Genre Purse. Physa. Draparnaud.

N. 65. PसYSE DEe xoUsses. Physa hypnorum.

Draparmaud, Loc. cit. p. 55, $\mathbf{n}^{\cdot} 3$, pl. 3, f. 12, 13.

Lamasck, Loc. cit. p. $157, \mathrm{n} \cdot 3$.

Blainville, Dict: sc. nat. t. 40, p. 142.

Grateloup, Loc. cit. p. 155, n. 2.

Coltard-des-Cherres, Loc. cit. F. 404, n. 2.

Kickx, Loc, cit. p. 53, n.63.

Michard, Loc. cit. p. 83, n-1.

Millet, Ioc. cit. p. $132, n \cdot 64$.

Bouiltet, Loc. cit. p. 65, n.75.

Bulta hypnoram. Mator et Racketl, Loc. cit, p. 127, r. 13,

pl. 4, fig. 3.

Turton, Loc. cit. p. 26, n.20.

Habite la plupart de nos fossés d'eaux vives; très-commune. Les œufs de ces Mollusques sont ovoïdes; ils ont enriron un millimètre de diamètre longitudinal, et sont réunis au nombre de trois à douze, dans des petites masses arrondies ou ovales, de quatre à dix millimètres de diamètre, de matière gélatineuse incolore et hyaline, enveloppées d'une très-fine membrane unie, incolore et transparente. Chaque individu pond ordinairement quarante à cinquante œufs, qui éclosent vers le seizième jour de leur ponte; les petits, comme tous ceux des autres trachélipodes aquatiques, n'atteignent leur dernier accroissement que vers la fin de leur seconde année.

N. 69. Pyyse des fortaines Physa fontinalis.

Draparnaud, Loc. cit. p. 54, 13. 1, pl. 3, f. 8, 8 .

Lamarck, Loc. cit. p. 156, n. 2.

Brard, Loc. cit. p. 167, pl. 7, f. 7, 8 .

Blainvilte, Dict. sc, nat. t. 40, p. 143

Des Moutins, Loc. cit. p. 59, n. 1.

Gratcloup, Loc. cit. p. $154, \mathrm{n} \cdot 1$.

Collari-des-Cherres, Loc, cit. p. 104, n. 1.

Kick, Loc. cit. p. $54, \mathrm{n} \cdot 65$.

Micherd, Loc, cit. p. $85, \mathrm{n}^{\circ}$.

i. 
Millet, Loz, cit. p. 132, n: 63 .

Bouiltes, Loc. cit. p. $66, \mathrm{n} \cdot 76$.

Bulla fontinatis. Maton et Rackett, Loc. cit. p. 127, n. 13,

pl. 4, fig. 1.

Turton, Loc. cit, p. 26, n· 18.

Habite la plupart de nos eaux stagnantes; commune. Ses œufs sont semblables à ceux de l'espèce qui précède.

\section{Genre Linnée. Limnea. Lamarck.}

N. 70. LIMNÉE VeNTRUE. Limnea auricubaria.

raparnaud, Loc. cit. p. 49 , n. 1, pl. 2 , f. $28,29,32$,

Lamarck, Loc. cit. p. 161, n. 7.

Brard, Loc. cit. p. 140 , pl. 5, f. $2,3$.

Blainville, Dict. sc. nat. t. 26, p. 459.

rateloup, Loc. cit. p. $164, \mathrm{n} \cdot 7$.

Collard-des.Cherres, Loc. cit. p. 105, n. 3.

Kick $x$, Loc. cit. p. $56, \mathrm{n} \cdot 68$.

Michaud, Loc. cit. p. $86, \mathrm{n} \cdot 1$.

illet, Loc. cit. p. $132, \mathrm{n} \cdot 65$.

ouillet, Loc. cit. p. $67, \mathrm{n} \cdot 77$.

Helixo aurioularis. Matom et Rackett, Loc. cit. p. 221, n.63.

Turton, Loc. cit. p. $68, \mathrm{n} \cdot 59$.

Habite les fossés des fortifications et les marais de Condette; ses œufs, au nombre de soixante à cent, sont hyalins et ont une forme ovoïde d'un millimètre et demi à un millimètre trois-quarts de diamètre longitudinal; ils sont disséminés, comme tous ceux de ses congenères, dans une matière gélatineuse de forme elliptique, con. tenue dans une membrane très-mince, lisse et transpa. rente, qui, chez cette espèce, a trente ou quarante millimètres de long sur huit à dix de large. Ces œufs éclosent quinze à seize jours après leur ponte.

\section{YY. 71. Liviée OVALE. Limnea ovata.}

Draparnaud, Loc. cit. p. $50, \mathrm{n} \cdot 2, \mathrm{pl} .2$, f. $30,31,33$.

Lamarck, Loc, cit. p. 161, n. 8. 
Brard, Loc cit. p. 142, pl. 5, f. 4, 5.

Des Moulins, Loc. cit. p. 62, n.5.

Blainville, Loc. cit. t. 26, p. 458.

Gralaloup, Loc. cit. p. $163, \mathrm{n} \cdot 6$.

Collard-des-Cherres, Loc, cit. p. 105, n. 4.

Kickx, Loc. cit. p. 5\%, n. 69.

Michaud, Loc. cit. p. 86, n.2.!

Millet, Loc. cit. p. $132, \mathrm{n} \cdot 66$.

Eouillet, Loc. cit. p. 67, n.78.

Habite presque toutes nos eaux stagnantes; très-commune et très-variée dans sa grosseur. Les paquets d'œufs de cette espèce n'ont que quinze à vingt millimètres de diamètre longitudinal, sur cinq à six millimètres de diamètre transversal; ils contiennent soixante à quatrevingts œufs de trois-quarts de millimètres de diamètre.

\section{N. 72. LIḾNée gLdTINeUse. Limnea glulinosa.}

Draparnuud, Loc. cit. p. $50, \mathrm{n} \cdot 3$.

Des Moutins, Loc. cit. p. 62, 6.

Blainville, Loc. cit. t. 26 , p. 458.

Grateloup, Loc. cit. p. $165, \mathrm{n} \cdot 8$.

Kick $x$, Loc. cit. p. 5อ , $\mathrm{n} \cdot 66$.

Michaud, Loc. cit. p. $88, \mathrm{n} \cdot 4$, pl. 16, f. 13,14 .

Millet, Loc. cit. p. $133, \mathrm{n}^{*} 6 \%$.

H. glutinosa. Maton et Rackell, Loc. cit. p. $222, \mathrm{n} \cdot 65$.

Turton, Loc. cit. p. $69, \mathrm{n} \cdot 63$.

Habite les marais de Condette; les paquets d'œufs de cette Limnée sont semblables à ceux de l'espèce qui pré. cède, mais n'en contiennent que trente à quarante.

N. 73. Lrmnée voYageUse. Limnea peregra.

Uraparnaud, Loc. cit. p. $50, \mathrm{n} \cdot 4$, pl. 2, f. 34, 35.

Lamarck, Loc. cit. p. $161, \mathrm{n} \cdot 9$.

Payraudeau, Loc. cit. p. 106, n. 232.

Blainville, Loc. cit. t. 26 , p. $45 \%$.

Des Moulins, Loć. cit. p. $63, \mathrm{n} \cdot \%_{6}$

Graletoup, Loc cit. p. $160, \mathrm{n} \cdot 3$. 


$$
76
$$

Cothard-dos.Cherres, Loc, cit, p. $105, n \cdot 5$

Kiohw, Loc. cit. p. 5\%, n. 70 .

Michaud, Loc. cit. p. 88, n. 5 .

Millet, Ioc. cit. p. 133, n 68.

Bowittet, Loe. cit. p.68, n. 79.

H. petris. Matom of Racketb, Loc. cit. p. $219, n \cdot 60$, pl. 5 , fig. $8 *$.

Twiton, Loc. cit. p. $67, \mathrm{n} \cdot 58$.

Habite les fossés des fortifications et plusieurs autres fossés et mares du département; commun. Ses œufs sont semblables à ceux de la Limnée ovalé.

N. 74. Limnée stagnale. Limnea siagnalis.

Draparnaud, Loc. cit. p. 51, n. 5, pl. 2, f. 38,39 .

Lamarck, Loc. cit. p. $159, \mathrm{n} \cdot 2$.

Brard, Loc. cit. p. 133 , pl. 5 , f. 1.

Blainville, Loc. cit. p. 45\%, t. 26.

Dos Moulins, Loc. cit. p. $61, \mathrm{n} \cdot 1$.

Grateloup, Loc. cit. p. 15\%, n-1.

Cothard-des-Cherpes, Loc. cit. p. 105, n- 1

Kicks, Loc. cit. p. 58, n・ $1_{1}$.

Michaud, Loc. cit. p. 89, n. \%

Millet, Loc. cit. p. 133, n` 69.

Bouillet, Loc. cit. p. $69, \mathrm{n} \cdot 80$.

H. stagnatis. Maton et Rackett, Loc. cit. p. 214, n. 54 .

Turton, Loc. cit. p. $65, n^{*} 52$, f. 69.

Habite les marais de Condette et de Camier, les prin. cipales mares, et les fossés des fortifications du département; irès-commune. Ses œufs ont souvent deux millimètres de diamètre, et sont contenus, au nombre de cent à cent trente, dans des masses gélatineuses elliptiques, de trente à quarante millimètres de longueur, sur dix à douze de largeur.

N. 75. Limnéb des Mabais. Limnea palustris.

Draparnaud, Loc, cit. p. 52, n. 6, pl. 2, f. $40,42, \mathrm{et}$ pl. 3, fig. 1, 2.

Lamarck, Loc. cit. p. $160, \mathrm{n} \cdot 3$.

Brard, Loc. cit. p. 136 , pl. 5, f. 6,7 . 
Payraudeau, Loc. ct. p. 106, n'233.

Btainville, Dict. sc. nat. t. 26, p. $45 \%$.

Des Moutins, Loc. cit. p. 61, n. 2.

Grateloup, Loc. cit. p. $159, \mathbf{n} \cdot 2$.

Collard-des-Cherres, Loc. cit. p. 105, n. 2.

Kichx, Loc. cit. p. 59, n. 72.

Michaud, Loc. cit. p. $89, \mathbf{n} \cdot 8$.

Millet, Loc. cit. p. 133, n. 70.

Bouillet, Loc. cit. p. 70, n-81.

H. palustris. Maton et Rachett, Loc cit. p. 216, $\AA^{2} 56$, pl. 5, fig, 8 .

Turton, Luc. cit. p. $66, \mathrm{n} \cdot 54$.

Habite les fossés aquatiques de nos prairies, nos mares ct nos rivières; très-commune et très-variée dans sa grosseur et dans sa couleur qui n'est que le résultat de l'incrustation limoneuse des licux qu'elle habite. Les masses gélatineuses cylindriques, que cette espèce produit, n'ont pas plus de quinze à vingt millimètres de longucur s!t? cinq à six de largeur; elles contiennent le plus sonvent soixante à quatre-vingts œufs oroildes de trois-quartş aे un millimètre de diamètre.

N. 76. Limsév petite. Limnea minuta.

Draparnaud, Loc. cit. p. $50, \mathrm{n} \cdot \mathrm{S}, \mathrm{pl} .3, \mathrm{f} .5-7$.

Lamarck, Loc. cit. p. 162, n. 12.

Brard, Loc. cit. p. 62.

Blainville, Dict. 8c. nat. t. 26, p. $45 \%$.

Des Mioutins, Loc. cit. p. $62, \mathrm{n} \cdot 4$.

Grateloup, Loc. cit. p. $162, \mathrm{n} \cdot 5$.

Collard-des-Cherres, Loc. cit. p. 106, n. 6.

Kicks, Loc. cit. p. $60, \mathrm{n}: 75$.

Michaud, Loc. cit. p. $89, \mathrm{n} \cdot 10$.

Millet, Loc. cit. p. 134, n.72.

Bouillet, Loc cit. p. 71, n. 83.

H. fossaria. Maton ét Rackctt, Loc. cit. p. 217, n. 5\%, pl. 5, f. 9.

Turlon, Loc. cit. p. $66, \mathrm{n} \cdot 55$.

Mabite sur la vase des bords de nos sourers, misicaux : 
mares et rivières, sur laquelle elle dépose ses œufs, sans les fixer aux tiges de plantes aquatiques comme ses congenères; ceux ci sont réunis dans des petites masses arrondies de cinq à six millimètres de diamètre qui contiennent rarement plus de quinze à vingt œufs d'environ un demi millimètre de diamètre. Je n'ai jamais observé celte espèce dans l'eau; elle vit à-peu-près comme les Ambretles; j'en ai conservé pendant plusieurs mois sur de la terre humide, où ils vivaient parfaitement, et toutes les fois que je les meltais dans l'eau je les trourais quelques instants après au-dessus de sa surface. Très-commune et aussi trìs-variée dans sa grosseur; ceux qui habitent les bords de nos rivières ont ordinairement six millimètres de lon gueur sur trois de largeur, tandis que ceux qui virent sur les bords des sources et des mares ont jasqu'à douze millimètres de longueur sur six millimètres et demi de largeur.

Genre Ancrue, Ancylus. Geoffroi.

N. 7\%. ANCyle des lacs. Ancylus tacustris.

Draparnaud, Loc. cit. p. $47, \mathrm{n} \cdot 1$, pl. 2, f. 25.27.

Lamarch, Loc. cit. p. 27, n. 1.

Grateloup, Loc, cit. p. 168 , п. 2 .

Kick $x$, Loc. cit. p. 78, n. 97.

Michaud, Loc. cit." p. $90, \mathrm{n} \cdot 1$.

Millet, Loc cit. p 134, n. 73.

Bouillet, Loc. cit. p. 72, n. 84 .

Palella oblonga. Malon et Rackelt, Loc. cit. p. 233, n. 8 . Turton, Loc. cit. p. 138, n.10.

Mabite la rivière de $\mathbb{W}$ imille et les marais de Condette, sur les plantes aqualiques et sur les coquilles des autres mollusques. Ses œufs, absolument semblables à ceux du Planorbis vorlex, sont réunis comme cux dans des pelites capsules ovigères, orbiculaires, mucoso-cornées et 
striées, qui en contiennent ordinairement cinq à douze; le développement des embryons s'opère aussi de la même manière, mais plus lentement, puisque ceux de ces Ancyles mettent vingt-quatre à vingt-six jours à éclore, tandis que ceux des Planorbes éclosent au buut de dix à donze jours.

Je pense que les Ancyles seraient mieux placés en tète de la famille des Limnéens qu'à son extrémité, lcurs animaux ayant plus de rapport arec ceux des Planorbes qu'arec ceux des Limnées.

N. 78. Ancrle fluviatile. Ancylus fuviatilis.

Draparnaud, Loc. cit. p. 48, n· 2, pl 2, f. $23,24$.

Lamarck, I.oc. cit. p. 27, n.2.

Brard, Loc. cit. p. 200 , pl. 7, f. 3.

Des Moulins, Ioc. cit. p. 63, n* 1 .

Grateloup, Loc. cit. p. 16\%, n. 1 .

Kickx, Loc. cit. p. 77, n· 96.

Michaud, Loc. cit. p. $90, \mathrm{n} \cdot 2$.

Millet, Loc. cit. p. 134, n. 74.

Bouillet, Loc. cit. p. 73, n' Sä.

Patella tacustris. Maton et Rachett, Loc. cit. p. 232, n*7. Tarton, Loc. cit. p. $138, \mathrm{n} \cdot \mathrm{S}$.

Habite nos rivières et nos ruisseaux dont le fond est pierreux; ceux qui vivent dans la rivière de Wimille sont énormes en proportion de ceux qui virent dans nos ruisseaux; ils different anssi de couleur: les premiers sont gris comme leur coquille, tandis que les autres sont noirâtres et leur coquille aussi; les premiers ont neuf a dix millimètres de longueur sur six à sept de largeur et cinq de hauteur; les scconds n'ont rue six à six millimètres et demi de longueur sur cinq de largeur et trois de hautenr. Sur les premiers l'organe de la respiration est très-développé; il cst triangulaire, arrondi ì son exlrémité; large à sa base d'environ un millimètre et demisur 
un milliwetre de havtour; il est assoz épais, blanchútre ct silué au milicu đa côté gauche entre le pied at le man tean. Ee n'ai obscrvé que les oufs de la variété de nos ruisseaux; ils sont ordinairement au nombro de quatre a six dans uno petite capsule orbiculaire de trois millimètres de diamètre. Ces œufs ne sont point ovoïdes comme ceux de l'espèce qui précède; ils sont réunis en une seule masse orbiculaire remplissant les deux tiers de la capsule, et divisée par des lignes qui forment autant de triangles qu'il y a d'embryons. (1)

\section{Genre Paluding. Paludina. Lamarck.}

N. 79. Paludine vivipares. Paludina vieipari.

Lamarck, Loc. cit. p. $1 \%$, n-1.

Brard, Loc. cit. p. 174, f. 1, pl. 7.

Des Moulins, Loc. cit. p. 64, n.1.

Blainville, Ioc. cit. p. 302 , t. $3 \%$.

Graleioup, Loc. cit. p. $170, \mathrm{n} \cdot \mathbf{\text { . }}$

Collard-des-Cherres, Loc, cit. p. 107, n-1.

Kichs, Loc. cit. p̀. 73, n. 91.

Mlichand, Loc. cit. p. $\$ 3, \mathrm{n} \cdot 2$.

Milict, Loc, cit. p. 134, n. 75.

Cycl. viviparum. Draparnaud, Loc. cit. p. 34, n*5, pl. 1, Aig. $16,1 \%$.

H. vivipara. Maton ot Rackett, Loc. cit. p. $205, \mathrm{n} \cdot 3 \%$. Turton, Loc. cit. p. $59, \mathrm{n} \cdot 39$.

Habite les marais de Condette, le canal de Calais et les fossés aquatiques des environs d'Aire et de Saint-Omer; très-commune. Cette Paludine et la suivante sont ovovivipares, et contienuent, en automne, vingt à trente oufs dans leur matrice; ces œufs ont depuis trois millimetres

(1) Voyez ma description de la ponte et du développenent des foetus de l'Ancylus fruvialilis; aux Actes de la Soc., Linn. de Bordeaux, t. 5. page 310 ; et au procès-verbal de la Société d'Agriculture de Boulognesur-Mer, année 1832, pages 238 à 141. 
de diametre jusquà sept millimetres, et sont d'autant plus développés, qqu'ils approchent de l'ouverture de la coquille; l'envoloppe externe des plus petits est blanche et opaque; elle devient de plus on plus translucide, au fur et à mesure qu'ils grossissent; les embryons se développent dans lo corps de leur mère, et ne sont déposés que lorsqu'ils ont la forme qu'ils doivent conserver. Leur coquille a, alors, quatre tours de spire el six à sept millimètres do diamètre transversal; elle est entièrement couverte d'une granulation très-fine, très-serrée et trèsrégulière; elle est tricarénée, et ces carènes sont garnies de nombreux petits poils roux recourbés en arrière, formés par trois petits lobes triangulaires du bord du man.. teau, qui ont environ un millimètre de longueur, et sont ¿oujours renversés sur la coquille; ils sont situés à la place où seront plus tard les trois bandes noires qui ornent ce manteau, ot dont une seule commence à se former, les deux autres n'étant encore annoncées que par des petites taches grisâtres plus ou moins éloignées les unes des autres, mais rangées sur une même ligne. En grossissant, cette coquille perd insensiblement sa granulation et ses carènes, et le manteau ses appendices; parvenu au quart de la grosseur qu'elle doit aroir, tout est disparu : on voit alors très-distinctement les trois bandes noires du manteau. Les petites Paludines ne commencent à être expulsées du corps de leur mère que vers la fin du deuxième mois, et cette expulsion nécessite plusieurs jours pour être terminée, parce qu'elles ne surtent que deux, trois ou quatre au plus par vingt-quatre heures.

2. S0. Paudine agathe. Patudira achatina.

Lamarch, Loc cit.. p. 174, n-2.

Blainvitte, Dict. sc. nat. t. 37, p. 303

Grateloup. Loc. cit. p. 171, n. 2 . 
Kick $x$, Loc. cit. p. $74, \mathrm{n} \cdot 92$.

Michaud, Loc. cit. p. $93, \mathrm{n} \cdot 3$.

Millet, Loc. cit. p. $135, \mathrm{n} \cdot 76$.

C. achatinum. Draparnaud, Loc. cit. p. $36, \mathrm{n} \cdot 6$, pl. $1, \mathrm{f} .18$.

Habite les fossés aquatiques des environs d'Aire; plus rare que la précédente.

N. 81. Paludine sale. Paludina impura.

Lamarck, Loc. cit. p. $175, \mathrm{n} \cdot 5$.

Brard, Loc. cit. p. 183, pl. \%, f. 2 .

Blainville, Loc. cit. p. 303 , t. 37.

Des Moutins, Loc. cit. p. 65, n· 2.

Graleloup, I.oc. cit. p. $172, \mathrm{n} \cdot 3$.

Collard-des-Cherres, Loc. cit. p. 10\%, n.2.

Kick $x$; Loc. cit. p. 74, n. 93.

Michaud, Loc. c1t. p. $93, \mathrm{n} \cdot 4$.

Millet, Loc. cit. p. $135, \mathrm{n} \cdot \% \%$.

Bouillet, I.oc. cit. p. 74, n. 86 .

C. impurum. Draparnaud, Loc. cit. p. $36, \mathrm{n} \cdot 7, \mathrm{pl} .1$, fig. $19,20$.

II. tentaculata. Naton et Rackett, Loc. cit. p. 220, n・61. Turton, Loc. cit. p. $68, \mathrm{n} \cdot 61$.

Habite presque toutes les rivières et eaux stagnantes de notre département; très-commune.

La ponte de ce Mollusque est on ne peut plus remarquable; clle a licu de Mai en Août, ct se compose ordi nairement de trente à soixante-dix œufs, globuleux, légèrement succinés, hyalins; ils ont deux millimètres de diamètre, et sont rangés sur trois rangs; ils forment ainsi une bande de quinze à trente-cing millimètres de longueur, sur environ cinף millimètres de largeur; les œufs, situés au centre de cette bande, sont si comprimés, qu'ils ont une apparence carréc : cetle bande est fixée sur les pierres ou sur les tiges des grandes plantes aquatiques. Lorsque celte Paludine est disposée à pondre, elle cherche, sur le corps sous-marin ou elle sc trouve, l'endroit 
le plus lisse, et commence à nettoyer avec sa bouche la place où elle veut déposer ses premiers œufs; cela fait, elle contracte son plan locomoteur de manière à le rendre un tiers plus court qu'il est lorsqu'elle rampe, ce qui le rend en même temps un tiers plus large, altitude qu'il conserve pendant toute la durée de la ponte : alors elle cesse le mourement de sa bouche, relève le centre de l'extrémité antérieure de son plan locomoteur, afin d'en former un petit canal destiné à recevoir l'œuf; elle rentre un peu la tête dans sa coquille, et, en en appuyant le sommet sur la columelle, dirige son mufle vers l'orifice de la cavité pulmonaire, où paraît à l'instaut un œuf, que ce dernier reçoit et guide jusqu'au petit canal, qui, en s'abaissant, le recouvre et le fait glisser, en conservant la ligne médiane entre le plan locomoteur et le corps sous-marin sur lequel ce plan le fixe lorsqu'il est arrivé à-peu-près vers son ticrs postérieur. La Paludine nettoie de nouveau le corps sous-marin, jusqu'à ce qu'un nouvel œuf soit prêt à être déposé : cet œuf est reçu et guidé comme le premier, au côté droit ou gauche duquel il vient se placer, mais en le dépassant de moitié; le troisième est placé de la même manière, au côté opposé; de sorte que ces deux derniers œufs, collés au premier par environ un quart de leur circonférence, forment à-peuprès un angle droit, dont le vide est rempli par la moitié du quatrième œuf, qui reçoit, au fur et à mesure de leur expulsion, sur les côtés de son autre moitié, deux nouveaux œufs qui s'y fixent et laissent encore entre eux un vide destiné à recevoir la moitié du septième. Ces œufs continuent à être expulsés et placés ainsi jusqu'à la fin de la ponte, qui, lorsqu'elle est terminée, forme une bande semblable à celle décrite plus haut, qui est tou. jours un peu moins large que le plan locomotenr; celui-ci 
devance toujours d'environ deux millimètres la derniiro rangée d'œufs, et recouvre, pendant toute la durée de la ponte, en arançant très-lentement, les neuf a dix derniers œufs pondus : en sorte que ces œufs, mettant un intervalle de ciny à huit minutes entre leur expulsion. chacun d'eux resto soixante-dix à quatre-vingts minutes protégé par ce plan, temps euffisant pour qu'ils puissent s'agglutiner entre eux, ainsi qu'au corps sous-marin. Ces bandes, toujours de trois rangs d'œufs lorsqu'elles proviennent d'individus adultes, n'en ont souvent que deux lorsqu'elles sont produites par de jeunes individus, ces Mollusques reproduisant long-temps arant d'avoir atteint leur dernier degré d'accroissement; le nombre de ces œufs est aussi bien plus nombreux chez les premiers que chez les derniers; mais ces œufs, chez les uns comme chez les autres, ont toujours deux millimètres de diamètre; ils éclosent vingt à vingt-cinq jours après leur ponte, et ne sont adultes qu'à la fin de leur seconde année.

N. 82. Paldine aigoe. Paludina acrala.

Des Moulins, Loc. cit. p. 67, n. 7 .

Grateloup, Loc. cit. p. $175, \mathrm{n} \cdot 7$.

Michaud, Loc. cit. p. $100, \mathrm{n} \cdot 14$.

C. acutum. Draparnaud, Loc. cit. p. $40, \mathrm{n} \cdot 15$, pl. 1 , f. 23.

Habite les fossés d'eaux saumâtres des prairies de $C_{a-}$ pécure; très-commune. Son animal a le corps noirâtre, plus foncé vers la tête, qui est proboscidiforme et porte deux tentacules assez longs, cylindriques et annelés do noir et de gris; yeux subpédonculés, placés un peu en arrière de la base externe des tentacules; organes génitaux au côté droit, organe mâle à la base du tentacule de ce côté, et l'organe femelle dans la cavité respiratrice. Plan locomoteur bilobé en avant, ot arrondi postérieure- 
ment. Longueur do la coquille, sopt ì huit millimètros; largour, trois millimètres un quart.

N. 83, Paludine sadmatre. Patudina muriabica.

Lamark, Loc. cit. p. 175, n' 6.

Elainville, Ioc. cit. t. 37 , p. 303.

Des Moulins, Loc. cit. p. 67, n- 6 .

Grateloup, Loc. cit. p. $175, \mathrm{n} \cdot 6$.

P. anatina. Mlichaud, Loc. cit. p. $100, \mathrm{n} \cdot 15$.

C. anatinum. Draparnaud, Loc. cit. p. $37, \mathrm{n} .8, \mathrm{pl} 4$, fig. $24,25$.

Corps gris, marqué de chaque côté de petites bandes noires qui lui donnent une apparence zébrée; tête noirâtre, mufle très-allongé et violet foncé; deux tentacules grris, portant à leur extrémité un petit cercle noir; yeux noirs, situés au sommet de deux petits pédoncules blancs placés à la base externe des tentacules; organes de la génération au côté droit. Plan locomoteur assez large, blanchâtre, carré antérieurement, et arrondi à son extrémité postérieure. La coquille a quatre millimètres de longueur sur deux de largeur; elle a six tours de spire, et non quatre à quatre et demi, comme le disent plusieurs auteurs. Elle vit dans l'eau salée, ế est si commune dans la belle saison, qu'elle tapisse toute la surface de la rase du bassin du port de Boulogne.

\section{Genre Valver. Valvata. Muller.}

N. 84. Valvéb PIscinale, Valvata piscinalis.

Lamarch, Loc. cit. p. $172, \mathrm{n} \cdot 1$.

Blainville, Loc. cit. t. 56, p. 462

Des Moutins, Loc. cit. p. 64, $n=1$.

Grateloup, Loc. cit. p. $176, \mathrm{n} \cdot 1$.

Colhard-des-Cherres, Loc. cit.p. $106, \mathrm{n} \cdot 1$.

Dlichaud, Loc cit. p. $101, \mathrm{n} \cdot 1$.

Millet, Loc. cit. p. 135, n. 79.

Bouillet, Hoc. cit. p. $76, \mathrm{n} \cdot \mathrm{SS}$. 
V. obtusa. Brard, Loc. cit. p. 190, pl. 6, f. $1 \%$.

Kiokx, Loc. cit. p. $70, \mathbf{n} \cdot 88$.

Turbo fontinalis. Maton et Rackett, Loc. cit. p. $168, n \cdot 26$. Turton, Loc. cit. p. 20\%, n· 34.

Habite les eaux vives et courantes; très-commune. Dans les mois de Mai à Août, ce Mollusque dépose ses œufs, au nombre de soixante à quatre-vingts; tous sont contenus dans une seule capsule sphérique, de deux millimètres et demi de diamètre, de matière coriacée jaunâtre: cette capsule est fixée, par un des points de sa circonférence, aux pierres ou aux tiges des plantes aquatiques. Elle a la plus grande analogie avec les capsules ovigères des trachélipodes purpurifères; mais, ce que je n'ai jamais observé dans le développement des embryons de ces derniers, et qui est particulier à cette $V$ alvée, c'est que ses embryons ne peuvent se développer entièrement dans leur capsule ovigère, où ils sont tellement comprimés, que, vers le douzième jour de sa ponte, cette capsule se déchire à sa partie supérieure, et laisse échapper environ les trois-quarts de son contenu, qui, tenant toujours à ce qqui reste dans la capsule, forme néanmoins, en dehors, une masse arrondie quatre fois aussi grosse qu'elle. Gette masse est composée de matière gélatineuse incolore et transparente, dans laquelle les œufs sont disséninés : ces $œ u f s$ ont environ un millimètre de diamètre, et contiennent un albumen aussi limpide que l'eau, dans lequel nage le petit embryon, qui a déjà les formes qu'il doit conserver; il remplit à-peu-près la moitié de l'œuf, dont il ne doit sortir que quatre jours plus tard, c'est-à-dire lo seizième de sa ponte.

N. 85. VALVÉt SPIRORBE. Valvata spirortis.

Draparnaud, Loc. cit. p. 41, n. 1, pl. 1, f. 32.33.

Brard, Loc cit. p. $18 \%$, pl. 6 , f. 15, 16 . 
Blainvitlo, Dict. sc. nat. t. 56, p. 463.

Grateloup, Loc. cit. p. $178, \mathrm{n} \cdot 3$.

Michaud, I.oc. cit. p. 101, n.2.

Habite une petite mare formée par une source située près du Pont-de-Briques; commune.

N. 86. Vatvée planorbe. Valvata planorbis.

Draparnaud, Loc. cit. p. 41 , n- 2, pl. 1, f. 34-35.

Brard, Loc. cit. p. 188, pl. 6, f. 18-19.

Blainville, Dict. sc, nat. t. 56 , p. 463.

Des Moutins, Loc. cit. p. $64, \mathrm{n} \cdot 2$.

Grateloup, Loc. cit. p. 177, n. 2.

Collard-des-Cherres, Loc. cit. p. $106, \mathrm{n} \cdot 2$.

Miohaud, Loc. cit. p. 101, n' 3.

Millet, Loc. cit. p. $136, \mathrm{n} \cdot \mathrm{S} 0$.

Bouillet, Loc. cit. p. $76, n \cdot 89$.

V. cristata. Kick $x$, Loc. cit. p. $71, n \cdot 89$.

Turbo oristatus. Maton et Racholt, Loc. cit. p. 169, n. 28. Turton, Loc. cit. p. 22\%, n. $8 \%$.

Habite les marais de Conclette, dans les fosses aux tourbes; assez commune.

N. 8\%. VALvíe mente. Valvata minuta.

Draparnaud, Loc. cit. p. $42, \mathrm{n} \cdot 3, \mathrm{pl} .1$, f. 36.3S.

Blainville, Dict. sc. nat. t. 56, p. 463 ,

Kicks, Loc. cit. p. 72, n'90.

Michaud, Loc. cit. p. 101, n. 4.

Habite avec l'espèce précédente.

\section{ORDRE III.}

\section{CONGHIFÉRES. Conchifera. Lamarck.}

Genre Anodonte. Anodonta. Bruguière.

N. 88. Anodontr des camards, Anodonta analina.

Draparnaud, Loc. cit. p. 133, n 1, pl. 12, f. 2 。 
Lamarck, Loc. cit. p. $85, \mathrm{n} \cdot 2$.

Des Moulins, Loc. cit. p. $43, \mathrm{n} \cdot 2$

Grateloup, Loe. cit. p. 184, n. 2.

Coltard-des-Cherres, Loc. cit. p. 93, n. 1 .

Michars, Loc. cit. p. $405, \mathrm{n} \cdot 4$.

Millet, Loc. cit. p. $137, n \cdot 83$.

Bouillet, Loe. cit. p. 78, n.90.

Mytitus anatinus. Maton et Rackett, Loc. cit. p. 110, n. 10, pl. 3, A, fig. 4.

- avonensis. Turton, Loc. eit. p. 116, n' 19.

Habite les rivières de Wimille et d'Isque; assez commune.

N. 89. Anodontr mrtorgnes. Anodonta intermedia.

Lamarck, Loc. cit. p. $86, \mathrm{n} \cdot 10$.

Collard-des-Cherres, Loc. cit. p. 93, ․ 2.

Millet, Loc. cit. p. 137, $\mathrm{n} \cdot 84$.

Bouillet, Loc. cit. p. $79, \mathbf{n} \cdot 92$.

Habite les rivières la Lys et l'Aa; très-commune.

N. 90. Anodonte CYGNe. Anodonta cygnea.

Draparnaud, Loc. cit. p. 134, n.2, pl.11, f. 6, pl.12, f. 1.

Lamarck, Loc. cit. p. $84, \mathrm{n} \cdot 1$.

Brard, Loc. cit. p. 234 , pl. 10.

Des Moutins, Loc: cit. p. $43, \mathrm{n}: \mathrm{A}$.

Gratcloup, Loc. cit. p. $183, \mathrm{n} \cdot 1$.

Kick $x$, Loc. cit. p. 80, n. 99.

Michaud, Loc. cit. p. $105, \mathrm{n} \cdot 2$.

Millet, Loc cit. p. $136, \mathrm{n} \cdot 1$.

Bouillet, Loc. cit. p. $79, \mathrm{n} \cdot 91$.

Mytilus anatinus. Maton et Rackett, Loc. cit. p. 109, n. 9,

pl. 3, A, fig. 1.

oygneus. Turton, Loc. cit. p. 115, n. $1 \%$.

Habite presque toutes nos rivières et eaux slagnantes; très-commune et très - variée dans sa forme.

N. 91. Anodonte ventrue. Anodonta ventricosa.

Pfeiffer, 11, pl. 3, fig. 1-6.

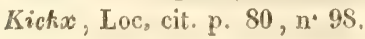


A. Testâ ovátâ, fragili, ventricosa, anterius rotundatâ, posterius productâ; margine aperturæ compresso, sinuato; natibus retusis; adulta 160 mill. longa; 82 alta; 48 crassa; tenuïs, rugosa, epiderme virescente obtexta, intus nitida, alba, cœrulœa vel margaritacea. (Pfeiffer.)

Habite la rivière la Lys, près Aire.

Genre Mulette. Unio. Brugnière.

N. 92. Molettr Des PeINTREs. Unio pictorum.

Draparnaud, Loc. cit. p. 131, n. 1, pl. 11, f. 1, 2, 4.

Lamarck, Loc. cit. p. 77, n· 32.

Brard, Loc. cit. p. 226 , pl. 8, f. 1.

Blainville, Dict. sc. nat. t. 56, p. $26 \%$.

Des Moulins, Loc cit. p. 41, n.1.

Grateloup, Loc. cit. p. 188, n• 3.

Coltard-des-Chorres, Loc. cit. p. 92, n- 4.

Kick $x$, Loc. cit. p. 84, n. 104.

Michaud, Loc. cit. p. 108, n· 3.

Millet, Loc. cit. p. $137, \mathrm{n} \cdot 88$.

Bouillet, Loc. cit. p. 80, n. 93.

Mya pictorum. Maton et Rackett, Loc. cit. p. 38, n. 9. Turton, Loc cit. p. $106, \mathrm{n} \cdot 20$.

Habite les fossés des fortifications de Saint-Omer, où il atteint une très-grande taille : je possède des individus qui ont dix centimètres de longueur, sur quarante-cinq millimètres de hauteur et trente millimètres d'épaisseur; très-commune. Dans les mois de Mai à Juillet, cette mulette, ainsi que la suivante, ont l'intérieur des feuillets des branchies externes rempli d'œufs, réunis en petites lames ovales, allongées, de six à dix millimètres de longueur, sur trois à quatre millimètres de largeur et environ un millimètre d'épaisseur; ces lames sont placées verticalement dans le sens transversal de ces feuillets branchiaux, et contiennent chacune quinze cents à deux 
mille oufs globuleux, jaunâtres, d'environ un huitième de millimètre de diamètre, qui sont réunis par une matière albumineuse incolore. Chaque branchie externe contient soixante à soixante-dix de ces petites lames ovales : ce qui donnerait, pour chaque individu, un total d'environ 220,000 œufs ! L'animal expulse, par son tube branchial, une de ces petites lames à la fois.

N. 93. Mulette hosthés. Unio rosirata.

Lamarck, Loc. cit. p. 77, n· 31.

Blainville, Dict. sc. nat. t. 56, p. $26 \%$.

Kichs, Loc. cit p. 83, n• 103, f. 17, 18.

Michaud, Loc. "cit. p. 108, n. 4, pl. 16 , f. 25.

Je ne cite point, dans la synonimie de cette espèce, celle décrite sous ce nom dans le catalogue des Mollusques de l'Auvergne, de M. Bouillet, et nommée primilivement $U$. limagna par cet auteur, parce qu'elle en diffère considérablement, et qu'elle a les plus grands rapports avec l'U. requienii de M. Michaud.

Habite le canal d'Aire à Béthune; très-commune. Longueur, quatre-vingt-quinze millimètres; hauteur, trentequatre millimètres, et épaisseur, vingt-huit millimètres.

N. 94. Mulette rentéé. Unio tumida.

Blainville, Dict. sc. nat. t. 56, p. 266 :

Kickx, Loc. cit. p. 83, n. 102.

IIabite avec l'espèce qui précède; commune. Longueur, soixantc-quinze millimètres; hauteur, trente-huit millimètres; épaisseur, vingt-huit millimètres.

N. 95. Mulette obtuse. Unio batava.

Lamarck, Loc. cit. p. 78, n' 33.

Blainville, Dict. sc. nat. t. 56, p. 268.

Kiok $x$, Loc. cit. p. 85, n. 105, f. 19.

Michaud, Loc cit. p. 109, n. 5. 
Mitlel, Loc. cit: p. $138, \mathrm{n} \cdot 89$.

U. pictorum, v. B. Draparnaud, Loc. cit. p. 131, n: 1, pl. 11, fig. 3.

Mya batava. Maton et Rackelt, Loc. cit. p. 37 ; in 8 . Turton, Loc. cit. p. 105, n. 19.

Habite le canal d'Aire à Béthune; assez rare. Longueur, quarante - cinq millimètres; hauteur, vingt - cinq millimètres, et épaisseur, dix-neuf millimètres.

N. 96. Mitemte arquép. Unio arcuata, Nobis, (figurée, Voir la planche ci-jointe.) (1)

Coquille inéquilatérale, oblongue, fortement arquée supérieurement, et échancrée à son bord inférieur, obtusément anguleuse antérieurement; courbée obliquement, et arrondie à son extrémité postérieure. Disque fortement déprimé vers son centre : cette dépression s'étend obli= quement, en sélargissant vers le bord inférieur et $\mathrm{y}$ forme une légère échancrure qui rend le côté antérieur plus ventru que le postérieur. Test mince, recouvert d'un épiderme vert-jaunâtre, luisant, marqué sur son côté antérieur de lignes longitudinales légèrement courbées, d'un vert plus foncé, et de stries d'accroissement trèsprononcées, formant à l'extrémité, du côté postérieur, de nombreuses petites lames noirâtres. Charnière arquée; dents cardinales assez épaisses, comprimées, tranchantes et dentelées; dents latérales en forme de lame qui se divise longitudinalement en deux dans la valve gauche, et forme un sillon pour recevoir la lame de la valve droite; nacre assez brillante, blanche, et plus épaisso au

(1) Je prie mon ami, M. Charles Demarle, de vouloir bien agréer ici l'expression de toute ma reconnaissance et mes plus vifs remerciments, pour le dessin qu'il a bien voulu faire de cette coquille, ct l'exactitude avec laquelle son crayon habile en a tracé tous les caractères. 
côté antérieur qu'au postérieur, où elle est bleuâtre. Crochets tuberculeux entiers et très-espacés; ligament corné, peu épais, occupant toute la longueur de la charnière, et recouvrant, par son prolongement, l'énorme lunule en forme de losange, qui commence en arrière des crochets, et se termine à l'extrémité du bord antero-dorsal; profondément excavée, bordée d'une carène très-aiguë. Cette excavation, dont le fond est tout-à-fait plat, est remplie en entier par la portion antérieure du ligament, laquelle y est plus épaisse qu'ailleurs, et y laisse, après sa chûte, des impressions longitudinales en forme de stries. Ces stries sont produites par l'insertion successive des feuillets qui forment la racine du ligament. Caractère commun avec l'U riio Michaudiana de M. Charles Des Moulins, à qui j'ai communiqué mon espèce, laquelle, au dire de cesavant naturaliste, differe autant de la sienne que deux Unios puissent differer l'un do l'autre.

Longueur, soixante-quinze millimètres; hauteur, quarante millimètres; épaisseur au-dessous des crochets, vingt-quatre millimètres; au centre, ringt millimètres.

Habite les fossés de Saint-Omer, alimentés par la rivière l' $A a$.

\section{Genre Cxclade. Cyclas. Brugnière.}

N. 97. Crclade CORNÉ. Cyolas cornea.

Draparnaud, Loc. cit. p. 128, n・1, pl. 10, f. 1-3.

Brard, Loc. cit. p. 219 , pl. 8, f. 2, 3

Grateloup, Loc. cit.p. $190, \mathrm{n}-1$.

Michaud, Loc. cit. p. 115, n. 1.

Nillet, Loc. cit. p. $138, \mathbf{n} \cdot 92$,

C. rivicola. Lamarck, Loc. cit. t. 5, p. $558, n \cdot 1$.

Blainville, Loc. cit. t. 12, p. 279.

Collard-des-Cherres, Loc. cit. p. 94, n. 1.

Kick $x$, Loc, ci.p. $86,11 \cdot 106$. 


\section{$9^{3}$}

Tellina cornea. Maton et Rackelt, Loc. cit. p. $59, \mathrm{n} \cdot 20$.

Turton, Loc. cit. p. $179, \mathrm{n} \cdot 30$.

\section{Habite le canal d'Aire à Béthune; assez rare.}

N. 98. Cyclade riverine. Cyclas rivalis.

Draparnaud, Loc. cit. p. $129, \mathrm{n} \cdot 2$, pl. 10, f. $4,5$.

Brard, Loc. cit. p. 222, pl. 8, f. 4, 5.

Blainville, Dict. sc. nat. t. 12 , p. 275.

Des Moulins, Loc. cit. p. $40, \mathrm{n} \cdot 1$.

Graleloup, Loc. cit. p. $191, \mathrm{n} \cdot 2$.

Michaud, Loc. cit. p. 115, n. 2.

Millet, Loc. cit. p. 139 , n' 93.

Bouillet, Loc. cit. p. 85, n. 99.

C. cornea. Lamark, Loc. cit. t. 5, p. 558, n. 2.

Collari-des-Cherres, Loc. cit. p. 91, n. 2.

Kick $x$, Loc. cit. p. 87, n. 107.

Tellina cornea, var. Maton et Rackett, Loc. cit. p. 59, 2.20 . Turlon, Loc. cit. p. $179, \mathrm{n} \cdot 30$.

Habite toutes nos rivières el eaux stagnantes; trèscommune. Lorsque ce Mollusque expulse ses petits, ils ont déjà trois millimètres de diamètre, et sont très-comprimés. Pendant leur jeunesse, ils rampent parfaitement sur les plantes aqualiques, et à la surface de l'eau, comme les Physes limnées, etc. Souvent ils se fixent sur les premières au moyen d'un fil translucide, semblable au Byssus de certaines espèces de $V$ énus.

N. 99. Cyclade des lacs. Cyclas lacustris.

Draparnaud, Loc. cit. p. 130 , n* 3, pl.10, f. $6,7$.

Lamarck, Loc. cit. p. $559, \mathrm{n} \cdot 3, \mathrm{t} .5$.

Blainville, Dict. sc. nat. t. 12 , p. 279.

Kick $x$, Loc. cit. p. 88, n. 108.

Michard, Loc. cit. p. $116, n \cdot 3$.

Millet, Loc. cit. p. $139, \mathrm{n} \cdot 94$.

Bouillet, Loc. cit. p. $85, \mathrm{n} \cdot 100$.

Tellina tacustris. Maton et Rackelt, Loc. cit. p. 60, n. 21

Turtan, Loc. cit. p. $180, \mathrm{n} \cdot 31$.

Habite la rivière de Wimille; commune. 


\section{4}

N. 100. Cratade des fontaines. Cyclas fontinalis.

Draparnaud, Loc. cit. p. 130, n-4, pl. 10, f. 8, 12.

Lamarck, Loc. cit. p. $559, \mathrm{n} \cdot 7$, t. 5 .

Blainville, Dict. sc. nat. t. 12, p. 279.

Dos Moulins, Loc. cit. p. $41, \mathrm{n} \cdot 2$.

Graleloup, Loc, cit. p. 1:3, n. 4 .

Michaud, Loc. cit. p. $116, n \cdot 4$.

Millet, Loc. cit. p. 139 , n. $9 \%$

Bouillet, Loc. cit. p. $86, \mathrm{n} \cdot 101$.

Habite les marais de Condette et les fossés des fortificalions; commune.

N 101. Cyclade caurculée. Cyclas calyculata.

Iraparnaud, Loc. cit. p. 130, n. 5, pl. 10, f. 13, 14.

Lamarck, Loc. cit. t. 5, p. $559, \mathrm{n} \cdot 5$.

Blainville, Dict. sc. nat. t. 12, p. 279.

Des Moulins, Loc. cit. p. 41, n'3.

Grateloup, Loc. cit. p. $193, \mathrm{n}^{\cdot} 5$.

Collard-des-Cherres, Loc. cit. p. $92, \mathrm{n} \cdot 3$.

Kickx, Loc. cit. p. 89, n' 109.

Michaud, Loc. cit. p $116, \mathrm{n} \cdot 5$.

Millet, Loc. cit. p. 139, n. 96.

Habite les fossés de nos prairies et ccux des fortifications; commune.

N. 102. Cyclade Ies maraIs. Cyclas palustris.

Draparnaud, Loc. cit. p. 131, n. 6, pl. 10, f. $15,16$.

Des Moutins, Loc. cit. p. $41,114$.

Graleloup, Loc. cit. p. 192, n'3.

Michaud, Loc. cit. p. $116, \mathrm{n}^{\circ} 6$.

Millet, Loc. cit. p. 139, n' 95.

C. obliqua. Lamarck, Loc. cit. t. 5, p. $559, \mathrm{n} \cdot 4$.

Kick $x$, Loc. cit. p. $89, \mathrm{n} \cdot 110$.

Tellina amnica. Maton et Rackelt, Loc. cit. p. 60, n*22.

Turton, Loc. cit. p. $168, \mathrm{n}^{3} 3$.

Habite la rivière de Wimille; commune.

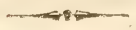




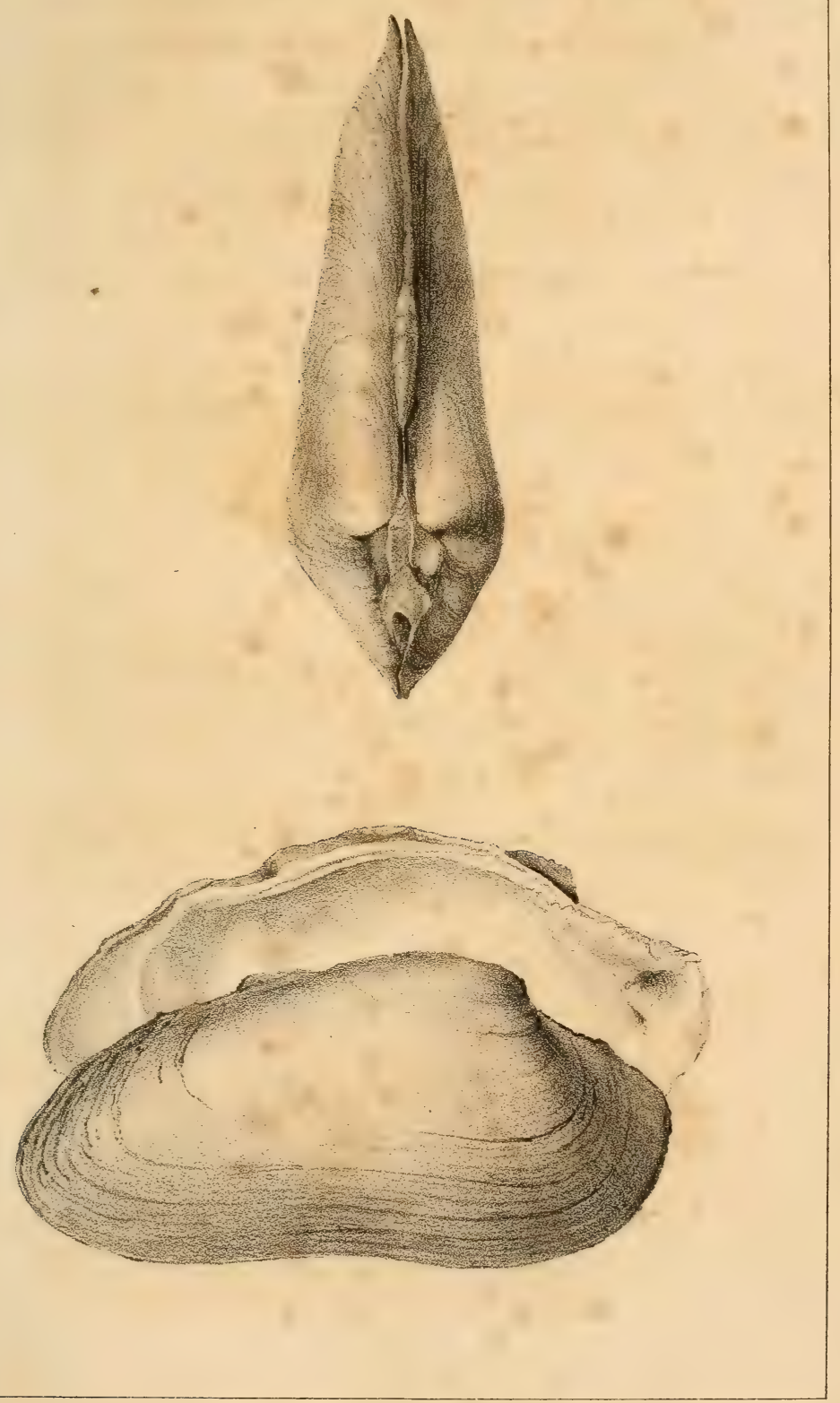

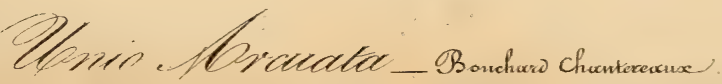




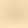

.

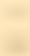

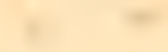

.

$$
\cdot
$$

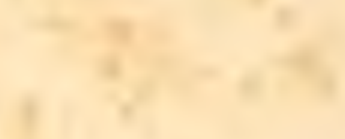

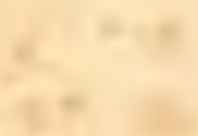

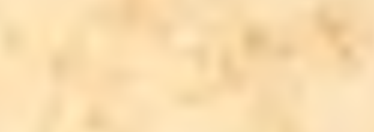







